\title{
Assessing Women's Menstruation Concerns and Experiences in Rural India: Development and Validation of a Menstrual Insecurity Measure
}

\author{
Bethany A. Caruso ${ }^{1, *(\mathbb{D})}$, Gerard Portela ${ }^{2}$, Shauna McManus ${ }^{3}{ }^{(\mathbb{D}}$ and Thomas Clasen ${ }^{4}(\mathbb{D}$ \\ 1 Hubert Department of Global Health, Rollins School of Public Health, Emory University, \\ Atlanta, GA 30322, USA \\ 2 Department of Epidemiology, Rollins School of Public Health, Emory University, Atlanta, GA 30322, USA; \\ gerard.thomas.portela@emory.edu \\ 3 Department of Biostatistics and Bioinformatics, Rollins School of Public Health, Emory University, \\ Atlanta, GA 30322, USA; shauna.mcmanus@emory.edu \\ 4 Gangarosa Department of Environmental Health, Rollins School of Public Health, Emory University, \\ Atlanta, GA 30322, USA; thomas.f.clasen@emory.edu \\ * Correspondence: bethany.caruso@emory.edu
}

Received: 31 March 2020; Accepted: 9 May 2020; Published: 15 May 2020

\begin{abstract}
Qualitative research has documented menstruator's challenges, particularly in water and sanitation poor environments, but quantitative assessment is limited. We created and validated a culturally-grounded measure of Menstrual Insecurity to assess women's menstruation-related concerns and negative experiences. With cross-sectional data from 878 menstruating women in rural Odisha, India, we carried out Exploratory (EFA) and Confirmatory (CFA) Factor Analyses to reduce a 40-item pool and identify and confirm the scale factor structure. A 19-item, five factor model best fit the data (EFA: root mean square error of approximation (RMSEA) $=0.027$; comparative fit index $(\mathrm{CFI})=0.994$; Tucker-Lewis index $(\mathrm{TLI})=0.989 ; \mathrm{CFA}$ : RMSEA = 0.058; CFI = 0.937; TLI $=0.925)$. Sub-scales included: Management, Menstrual Cycle Concerns, Symptoms, Restrictions, and Menstruation-Related Bodily Concerns. Those without access to a functional latrine, enclosed bathing space, water source within their compound, or who used reusable cloth had significantly higher overall Menstrual Insecurity scores (greater insecurity) than those with these facilities or using disposable pads. Post-hoc exploratory analysis found that women reporting experiencing tension at menstrual onset or difficulty doing work had significantly higher Menstrual Insecurity scores. This validated tool is useful for measuring Menstrual Insecurity, assessing health inequities and correlates of Menstrual Insecurity, and informing program design.
\end{abstract}

Keywords: gender; security; factor analysis; management; restriction; pain; menstrual health

\section{Introduction}

Increasing efforts to query, document, and share people's lived experiences of menstruation have resulted in recognition of menstruation as a public health issue [1], galvanized investment in and implementation of programs and policies [2,3], and inspired research priorities [4] and multi-sector collaboration and vision setting to improve circumstances and assessment strategies globally [5-7]. An ever-growing body of qualitative research, primarily focused on girls' menstruation experiences at school in low and middle income countries (LMICs), has shaped current understanding of how menstruation is experienced [8]. While qualitative research importantly provides detail of menstruation experiences, it is undertaken with small samples and cannot reveal how common and frequent experiences are among more representative populations. Quantitative assessment of 
menstruators' experiences is needed to elucidate priorities and inform programming and policy. The aim of this paper is to detail the process of creating a ground-up, locally-derived measure of Menstrual Insecurity, a construct that aims to represent the suite of experiences and concerns about and of menstruation, among women in rural Odisha, India.

A 2019 systematic review synthesizing findings from 87 qualitative publications on women's and girl's menstruation experiences in LMICs illuminates how these menstruation experiences can have broader impacts [8]. Specifically, their conceptual model illustrates that an array of antecedents (e.g., sociocultural context, resources, knowledge, environments) influence menstruation experiences (e.g., menstrual practices, confidence managing menstruation, shame and distress, symptoms), which in turn can impact social participation, education, employment, and psychological and physical health [8]. The authors highlight that some interventions have aimed to influence health and education (like school attendance) by improving antecedents (like knowledge or product access), without considering how experiences are important mediators of these relationships. The authors emphasize the need to develop measures of menstruation experience. The present research contributes a measure to assess menstruation experiences, which can be used independently and to determine how experiences influence health, employment, or other impacts.

There is limited understanding of women's experiences of menstruation in LMICs and the specific challenges and concerns they face. While the concerns that adults and adolescents report overlap greatly, adult health needs and experiences may differ through the life course, could result in different impacts on well-being and life outcomes, and are worthy of their own attention [9]. Notably, women in Odisha, India report that managing menstruation is a source of psychosocial stress [10] and that it is the most stressful of their sanitation-related behaviors [11]. Only 18\% (16 of 87) of the publications included in the review focused exclusively on women [8]. Women, from studies included both in the review and not, discuss the taboo and secretive nature of menstruation, behavioral expectations, varied restrictions, lack of practical or accurate biological information about menstruation, insufficient facilities and resources for management, and concerns about health due to menstrual patterns, symptoms, and flow [10-23].

Limited quantitative studies have documented experiences, behaviors, or concerns, like needing to abide by behavioral restrictions, having options for changing menstrual materials, or depending on others, like sexual partners, for materials [24-26]. However, menstruators do not have one concern or challenge alone. Women participating in qualitative interviews in rural Odisha, where the present research took place, reported 32 unique menstruation concerns that they believed women in their community experienced, including concerns about bathing at menstrual onset $(52 \%)$, washing $(51 \%)$ and drying (46\%) menstrual cloths, feeling general discomfort $(43 \%)$, being seen by people while managing menses $(37 \%)$, experiencing pain (34\%), feeling dirty $(30 \%)$, dealing with behavior restrictions $(30 \%)$, and worrying about irregularity (27\%) [22]. These data demonstrate that women's concerns include and extend beyond management to needs [12] and support the need to understand how prevalent and frequent an array of experiences and concerns are at the individual level in a broader population.

To fill the need to understand prevalence and frequency of menstruator's concerns and experiences, we aimed to develop a culturally-grounded measure to assess the suite of concerns and negative menstruation-related experiences that women in rural Odisha voiced. The measure is inclusive of-but not exclusive to-experiences managing menses; a scale assessing menstrual needs among adolescents has been created [27]. This broad approach, inclusive of participant-identified concerns and experiences, will enable understanding of the range of issues women in this population have and can enable future assessments of how concerns and experiences may impact menstruator's lives and inform program development. 


\section{Materials and Methods}

\subsection{Defining Menstrual Insecurity}

We refer to the complement of concerns and negative menstruation-related experiences women in this population face as 'Menstrual Insecurity'. Following best practice [28], we offer a preliminary definition of Menstrual Insecurity to be 'the suite of social, environmental, and biological concerns and negative experiences resulting from menstruation'. Our intentionally broad, preliminary conceptualization is informed by efforts to create culturally-grounded measures of food [29-31], water [32-34], and sanitation [35] insecurity. Researchers in these fields argue for extending understanding of insecurity constructs beyond biological needs to include the broader socio-cultural context, like social needs and experiences, which may impact well-being [31,32,34-36]. Our definition is intentionally broad and described as preliminary as we consider Menstrual Insecurity to be a concept to be iterated upon as research evolves, which has been demonstrated with the concepts of Water Insecurity [37] and Menstrual Hygiene Management [12,23].

\subsection{Setting}

Data for this research was collected in rural Puri district, Odisha, India, concurrently with data collected to create a measure of Sanitation Insecurity (March 2014-February 2015) [35]. At the time of data collection, $61 \%$ of rural inhabitants in India were estimated to practice open defecation [38]. In the India National Family Health Survey Report (NFHS-4, 2015-2016), which includes data collected just after the data from the present study, 71\% of women age 15-24 (the only age range queried) from rural India used cloth for menstruation, $15 \%$ used locally prepared napkins, and $37 \%$ used sanitary pads (multiple methods of use could be reported) [39]. A case-control study in Odisha found that women who used reusable cloths for menstruation were more likely to report symptoms of urogenital infection or have a lab-confirmed diagnosis of either bacterial vaginosis or a urinary tract infection than those using disposable pads [40].

Research was conducted in villages previously engaged in a cluster randomized controlled trial (May 2010-December 2013) to assess the health impacts of a latrine provision intervention [41-43]. While sanitation coverage increased in intervention villages, no reductions in diarrhea, soil-transmitted helminth infection, or child malnutrition attributable to the intervention were identified [41].

\subsection{Overview of Research Design}

The present research employed the mixed-methods approach that was used to create the measure of Sanitation Insecurity [35]. The approach leverages the perspectives and experiences of women, and is based on the ground-up, inductive approaches used to create measures of food and water insecurity [30,36]. The three-phase, sequential, mixed-methods design included a qualitative phase to understand the suite of women's menstruation concerns and experiences, a quantitative phase to capture the frequency and intensity of those concerns, and a measurement finalization phase involving various statistical analyses (See Figure 1).

This measure was intentionally developed separately from the measure of Sanitation Insecurity, which only included items related to urination and defecation [35]. The Sanitation Insecurity measure was intended to be applicable to all women. Because not all women menstruate, due to pregnancy, recent birth, and life stage, among other reasons, menstruation items were not included. Further, qualitative work identified menstruation concerns and experiences beyond those related to sanitation [12,22]. This Menstrual Insecurity measure can be used independently or in tandem with the Sanitation Insecurity measure. 


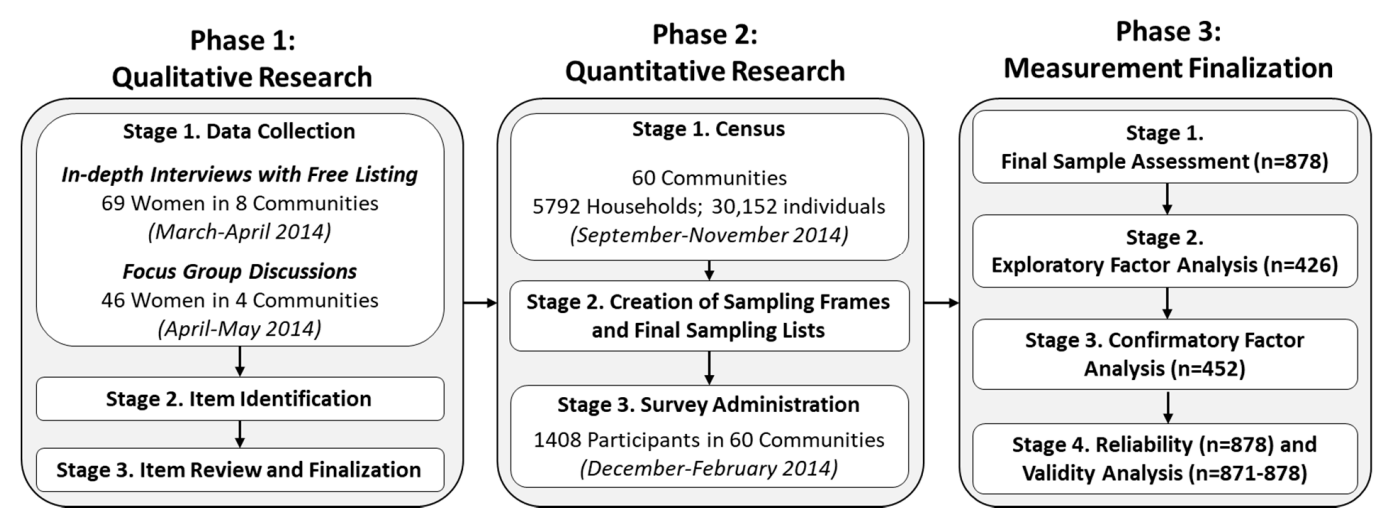

Figure 1. Schematic of Exploratory Sequential Mixed Methods Design Used to Create Menstrual Insecurity Measure.

\subsection{Phase 1: Qualitative Research}

Phase 1 involved qualitative data collection, preliminary measurement item identification, and review and finalization of items for phase 2 survey administration.

\subsubsection{Phase 1, Stage 1: Data Collection}

Qualitative data collection included Free-listing Interviews (FLIs) and Focus Group Discussions (FGDs). FLIs were held first to inductively identify concerns and experiences women had related to menstruation to inform items for the Menstrual Insecurity measure (March-April 2014). Free-listing is a methodology used among homogenous groups, in this case rural women from Odisha, India, to identify shared perceptions about a topic [44]. We asked women to list their concerns about menstruation and probed them to identify additional concerns at night or during the monsoon season. Interviews were conducted with women from eight villages ( 5 former intervention, 3 former control). Sixty-nine women were purposively selected for one-on-one interviews from four life stages: (1) unmarried ( $n=16)$; (2) married three years or less $(n=12)$; (3) married over three years $(n=22)$; (4) and women over 49 years of age $(n=19)$. These categories were intentionally selected given assumed variation in their sanitation and hygiene experiences [22]. Women no longer menstruating provided insights about when they were menstruating.

We then held eight FGDs $(n=46)$ with women from four different villages ( 2 former intervention, 2 former control), four with unmarried women $(n=23)$ and four with married women $(n=23)$ (April-May 2014). During the FGDs, we first asked women to share their perceptions of the concerns that 'women in their community' had about menstruation to capture new insights and not compel women to share personal information. We then asked for detail about the intensity and frequency of those concerns, and about concerns described in the FLIs if not already mentioned in the FGDs.

FLIs and FGDs were conducted in Oriya with trained research assistants. Each was recorded, then translated and transcribed into English. Further information about the qualitative methods, the participants engaged, and the findings related to sanitation insecurity [22] broadly and menstruation [12] specifically are reported elsewhere.

\subsubsection{Phase 1, Stage 2: Item Identification}

All FLIs were analyzed first to identify the full suite of concerns or negative experiences participants believed women in their community to have. We then determined the proportion of participants who reported each concern or experience. Thirty-two unique menstruation concerns were shared by 67 (97\%) of the 69 women interviewed. FGDs supported information gathered in FLIs (See Caruso 2017, including Supplemental Tables, for list and frequencies of concerns) [22]. Next, concerns were analyzed thematically to identify emergent grouping. We identified and sorted concerns into four themes, which included: Management, Restrictions or challenges to normal activities, Social needs and constraints, 
and Well-Being. Wording of the identified concerns in each theme was then adapted to create draft items. (See Supplemental Table S1 for Survey Items by theme.) The initial list of items included the full range of concerns noted, however monsoon-specific items were omitted due to irrelevance during the following anticipated data collection period. We hypothesized that these themes would emerge as factors in the final measure.

\subsubsection{Phase 1, Stage 3: Item Review and Finalization}

To finalize the pool of items, we conducted four rounds of review. First, to assess content validity, feedback on items was solicited from two external experts with experience research in sanitation and menstruation $[28,45]$. Second, the two research assistants who conducted the FLIs and FGDs provided additional assessment of content validity, specifically face validity, by confirming that items captured the range of concerns they heard and that wording was appropriate. The two RAs independently translated the items, then compared the translations item-by-item, and discussed alternative phrasings before finalizing translation. Third, as a preliminary means of pre-testing, each item was reviewed with the nine female enumerators hired to administer the survey using a cognitive interview approach [28,46]. In addition to having experience with survey data collection, including studies specific to sanitation and hygiene, all enumerators were from villages similar to those to be engaged in the next phase and were able to comment on the items regarding item content and translation. For each item, the RAs asked a team member to explain what the question was asking in their own words. Other team members were welcome to comment or offer an alternative understanding. The group then discussed, and changes to the item translation were made as needed. Fourth, the RAs and enumerator team piloted the items in a village like those to be surveyed. Team members noted any items that posed challenges for participants and suggested alternative phrasing. Final changes were made during a team meeting after the pilot.

The final tool included 40 items that asked women how often they had a particular menstruation-related experience during their last two menstrual periods: never, sometimes, often, or always (See Appendix A for the tool).

\subsection{Phase 2: Quantitative Research}

Quantitative research involved a census to create sampling frames, the creation of sampling frames and final sampling lists, and survey administration (See Figure 1).

\subsubsection{Phase 2, Stage 1: Household Census}

To identify eligible participants, we conducted a paper census in 60 of the former 100 trial villages. We aimed to survey 1440 participants from those 60 villages ( 30 former controls and 30 former recipients of the intervention) via a stratified, multi-stage, cluster sample design. Our sample size was powered for the parent study to detect effect sizes of sanitation insecurity on mental health outcomes (well-being, anxiety, depression, and distress) using a multilevel modeling (hierarchical modeling) approach with consideration for two levels: cluster level (e.g., former intervention status of the village) and individual level (e.g., latrine access, life stage, etc.) [47]. Results for that analysis are reported elsewhere [48]. We determined our base sample size of 60 clusters with 20 participants each (1200 participants) from a simulation study that demonstrated power to detect small $(d=0.20)$ direct and cross-level interaction effects for a continuous level-2 predictor to be greater than $96 \%$ [49]. We targeted 1440 participants (24 per village) to allow for attrition from: incomplete data, census errors misidentifying eligible participants, and unintentional multiple sampling of households.

We used the former intervention status of the village as a means of achieving sanitation coverage variability in our sample. Villages that had previously received the intervention were eligible if they had greater than $25 \%$ larine coverage. We determined coverage from the final trial data collection effort (December 2014) [41] assuming that coverage would not have changed markedly in the nine months since. Former control villages were eligible for inclusion if latrine coverage was less than $20 \%$. 
We gained feedback from a local non-government organization in Puri working to provide latrines in the former control villages to discern eligibility. Villages were ineligible if they had been engaged in the qualitative activities informing survey development.

The trained enumerator team visited each household in each eligible village to administer the census. The enumerator asked a representative from each of household to share information about household members, like sex, age, and marital status, and household water and sanitation access.

\subsubsection{Phase 2, Stage 2: Creation of Sampling Frames and Final Sampling Lists}

We created sampling frames from village census data to enable random selection of participants by life stage category. We sought women over age 18 from the four life stages previously noted. Sex, age, and marital status data were used to categorize each person censused. Those who did not belong to the four categories of interest (i.e., males, females under age 18) were not eligible. For each village, lists of eligible participants were created by category. Participants were then randomly selected from each list with the aim of including six participants per category per village.

\subsubsection{Phase 2, Stage 3: Survey Administration}

The survey was administered by the team of enumerators that piloted the items (December 2014-February 2015). Data collected included participant demographics, water and sanitation access, Sanitation and Menstrual Insecurity items, water and sanitation behaviors, menstruation behaviors, social support, and mental health outcomes. Women who self-classified themselves as currently experiencing menstruation were eligible to answer menstruation-related questions and have responses included in the current analysis. Enumerators were advised to engage only one woman per household. Enumerators read questions to the participants in Oriya and marked the responses provided on a paper survey, which took approximately one hour.

\subsection{Phase 3: Measurement Finalization}

Measurement finalization followed steps outlined in previous work [35]. We assessed the overall sample then carried out Exploratory (EFA) and Confirmatory Factor Analysis (CFA). We then assessed measure reliability and validity.

\subsubsection{Phase 3, Stage 1: Final Sample Assessment and Creation of Random Sub-Samples}

Participants were excluded from analysis if under age 18 and mistakenly sampled or had a household member previously surveyed (See Supplemental Figure S1 for Flow Diagram). Participant demographic information and relevant menstrual hygiene management practices were tallied by life stage to assess differences. We assessed the frequency, skewness, and kurtosis for each Menstrual Insecurity item (See Supplemental Table S2 for item response frequencies, skewness, and kurtosis) [50].

The overall sample was randomly split into two sub-samples to carry out EFA $\left(\mathrm{n}_{1}=426\right)$ and CFA $\left(n_{2}=452\right)$. We checked distributions, ran t-tests, and generated chi-square statistics to verify there were no significant differences in demographic and household information between the sub-samples (See Supplemental Table S3).

\subsubsection{Phase 3, Stage 2: Exploratory Factor Analysis}

EFA, recommended as a first step in measurement development [50], was carried out to determine measure factor structure. Using Cattell's scree test, a range for the number of optimal factors for the scale was determined. We assessed factor structures for models within this range to determine optimal fit [51].

Using the first sub-sample $\left(\mathrm{n}_{1}\right)$, we carried out EFA on all 40 menstruation items using Mplus 8.3 software (Muthén and Muthén, Los Angeles, CA, USA). Given the hypothesized intercorrelated nature of the factors, an oblique rotation (QUARTIMIN) was used [50]. As survey responses were categorical, we used a mean and variance adjusted weighted least square (WLSMV) parameter estimator that uses 
chi-square test statistics to determine the final number of factors for the measure and factor loadings of each item. We ran models with the number of factors within the range identified by Cattell's scree test (4-10 potential factors) and evaluated model fit statistics (root mean square error of approximation (RMSEA), comparative fit index (CFI), and Tucker-Lewis index (TLI), and theoretical fit to determine the final number of factors.

We assessed factor loadings and theoretical fit of each item within the factors to determine if an item should be dropped. We decided a priori to assess factor loadings based on cut-off points; a factor loading less than 0.3 indicated poor loading. Items were flagged as cross-loaded if the item loaded on two or more factors with a loading greater than 0.4 and the difference between the factor loadings was less than 0.3. First, we dropped poorly loaded items iteratively, dropping items with the lowest loadings first. Items that cross-loaded on multiple factors, or had the lowest loading below 0.6 , were dropped iteratively [52]. The final factor structure was assessed using knowledge of women's experiences with menstruation to ensure that items within factors and factors produced were appropriate and relevant. We used model fit statistics (noted above) to examine the final structure.

\subsubsection{Phase 3, Stage 3: Confirmatory Factor Analysis}

We used the second sub-sample $\left(\mathrm{n}_{2}\right)$ to test the factor structure identified through EFA. We used the Mplus 8.3 WLSMV estimator for CFA to determine the final model structure. The RMSEA, CFI, and TLI were used to examine the model fit. The same criteria as in the EFA was used to assess final factor loadings; any items below 0.3 were to be dropped from the model. Hierarchical confirmatory factor analysis was used to confirm that sub-scales form a unidimensional scale.

\subsubsection{Phase 3, Stage 4: Reliability and Validity Analysis}

We analyzed the reliability (internal consistency) of the full scale and each individual factor by calculating Cronbach's alpha using SAS 9.4 (SAS Institute, Cary, NC, USA). Pearson's correlations between the full scored measure and each individual factor, as well as between each factor were used to assess potential redundancy of factors.

As previously noted, content validity was assessed by two external experts and the two Research Assistants (RAs) who led FLIs and FGDs, and face validity was assessed by both the RAs and the enumerator team. Convergent validity was determined by assessing correlations between each subscale score and items from the survey that asked about thematically similar concepts. Specifically, for Subscale 1 (Restrictions), we assessed correlation of scores with traveling alone; Subscale 2 (Management) scores with having resources to change menstruation material; Subscale 3 (Symptoms) scores with infection symptoms, and Subscale 4 (Menstrual Cycle Concerns) scores with experiencing regular menstruation. Additionally, known-groups validation was used to assess discriminant validity, with two sample $\mathrm{t}$-tests being used to verify whether Subscale 5 (Menstruation-Related Bodily Concerns) scores differed by those reporting burning or itching in the vaginal area.

\subsection{Menstrual Insecurity Scores}

Sub-scale and overall scores were calculated as means (potential score ranges: 1.0-4.0). These numbers corresponded to the original response scale $(1=$ never, $2=$ sometimes, $3=$ often, $4=$ always $)$, with higher numbers indicating a greater mean frequency of occurrence. In addition, weighted scores were calculated, where standardization estimates from the variances of the sub-scales were used to weight each item before means were calculated.

Using SAS 9.4, we performed t-tests to determine if the mean scores were significantly different by life stage, ownership of a functional latrine, and type of menstruation material used. We also assessed differences in mean scores by responses to two items omitted from the scale. One assesses tension at menstrual onset, meaning a general feeling of anxiety about menstruation (not pre-menstrual stress or PMS, which can occur one to two weeks prior to menstruation), and the other assesses perceived difficulty doing regular work during menstruation. Analyses with these two items were not 
conceptualized a priori but were added after these items were omitted as a preliminary investigation of how these scores may vary by reported experiences of tension and work.

\subsection{Ethics}

Emory University's Institutional Review Board (Atlanta, GA, USA; IRB00072840) and KIIT University's Institutional Ethics Committee (Bhubaneswar, India; KIMS/KIIT/IEC/795/2014) granted ethical approval for this research. Participants provided informed oral consent prior to engagement.

\section{Results}

\subsection{Final Sample Assessment}

\subsubsection{Overall Sample}

We administered 1437 surveys; 29 were excluded because participants were under age 18 or another family member participated. Of the remaining 1408, the mean age of menarche for the total sample was 14.71 years-old; $17(1.2 \%)$ did not know and $3(0.2 \%)$ reported never having experienced menstruation. A total of $879(62 \%)$ reported they were currently experiencing menstruation and were eligible to answer questions in the menstruation module; 750 (85\%) self-reported regular menstruation and $129(15 \%)$ self-reported irregular menstruation. Of the $524(37 \%)$ who were not experiencing menstruation and did not complete the module, $76(14 \%)$ were pregnant, $45(9 \%)$ recently gave birth, and $403(77 \%)$ were menopausal. One respondent had missing data, so final measurement sample size was 878, including $338(39 \%)$ unmarried women (stage 1), $222(25 \%)$ women married for three years or less (stage 2), $308(35 \%)$ women married over three years, and $10(<1 \%)$ women over age 49 of any marital status (Table 1). (See Supplemental Figure S1 for Flow Diagram).

In the analytic sample, the average age of participants was 27, and the majority were Hindu (866; $99 \%)$, had at least some schooling $(809 ; 92 \%)$, and had a "below the poverty line" (BPL) card providing them access to government support (549; 63\%). Only 33\% (288) had access to a functional household latrine, and fewer had a primary drinking source $(242 ; 29 \%)$ or an enclosed bathing space within their household compound $(131 ; 15 \%)$. The majority were General Caste $(392 ; 45 \%)$ and relied exclusively on reusable cloth during menstruation $(611 ; 70 \%)$ (Table 1$)$.

Most women changed their materials in a private room in their home (782; 90\%). Among women who used disposable materials, almost all disposed of pads in a pond/river/stream $(172 ; 66 \%)$ or an outside trash pile $(70 ; 27 \%)$. Among women that reused materials, the majority washed cloths in a pond/river $(434 ; 71 \%)$ and dried them outside in the sun $(487 ; 80 \%)$. Women stored reusable materials hidden in their home $(303 ; 50 \%)$ or in the eaves of their house roof $(247 ; 41 \%)$ (See Supplemental Table S4 for menstruation-related behaviors).

\subsubsection{Menstruation Module Items}

The most commonly reported concerns were not related to management. Specifically, women reported at least sometimes worrying about not being able to participate in religious activities during menstruation ( $84 \%$ ); not being able to touch things during menstruation, which caused difficulties $(66 \%)$; experiencing a general feeling of tension at menstrual onset $(66 \%)$; experiencing stomach pains during menstruation (61\%); avoiding leaving the house during menstruation (46\%); and having difficulty doing their regular work during menstruation (43\%) (Table 2).

Participants most frequently responded 'always' to questions regarding physical symptoms during menstruation or limitations to their activities during menstruation, such as: "Experienced stomach pains during menstruation" (29\%) and "Worry about not being able to participate in religious activities" (29\%). Women most frequently responded 'never' to questions related to social concerns: "Worried that others knew I was menstruating" (98\%) and "Had people tease me because they knew I was menstruating" (99\%). 
Table 1. Demographic characteristics of participants, overall and by life stage, in rural Orissa, India.

\begin{tabular}{|c|c|c|c|c|c|c|c|c|c|c|}
\hline Characteristics & \multirow{2}{*}{\multicolumn{2}{|c|}{$\begin{array}{c}\text { All } \\
1437\end{array}$}} & \multicolumn{2}{|c|}{$\begin{array}{l}\text { 1. Unmarried } \\
\text { (UM) }\end{array}$} & \multicolumn{2}{|c|}{$\begin{array}{l}\text { 2. Recently Married } \\
\text { (RM) }\end{array}$} & \multicolumn{2}{|c|}{$\begin{array}{l}\text { 3. Married } \\
\text { (M) }\end{array}$} & \multicolumn{2}{|c|}{ 4. Over $49(\mathrm{OW})$} \\
\hline \multirow{2}{*}{$\begin{array}{c}\text { Total Surveyed }^{1} \\
\text { Mean Age at First Menstruation }\end{array}$} & & & \multirow{2}{*}{$\begin{array}{c}341 \\
13.66\end{array}$} & \multirow{2}{*}{\begin{tabular}{c|}
$24.2 \%$ \\
4.79
\end{tabular}} & \multirow{2}{*}{$\begin{array}{c}320 \\
13.65\end{array}$} & \multirow{2}{*}{$\begin{array}{c}22.7 \% \\
5.02\end{array}$} & \multirow{2}{*}{$\begin{array}{c}395 \\
14.87\end{array}$} & \multirow{2}{*}{$\begin{array}{l}28.1 \% \\
10.58\end{array}$} & \multirow{2}{*}{$\begin{array}{c}352 \\
16.49\end{array}$} & \multirow{2}{*}{$\begin{aligned} 25.0 \% \\
15.57\end{aligned}$} \\
\hline & 14.71 & 10.22 & & & & & & & & \\
\hline Don't Know & 17 & $1.2 \%$ & 0 & $0.0 \%$ & 1 & $0.3 \%$ & 6 & $1.5 \%$ & 10 & $2.8 \%$ \\
\hline Never Experienced Menstruation & 3 & $0.2 \%$ & 1 & $0.3 \%$ & 0 & $0.0 \%$ & 0 & $0.0 \%$ & 2 & $0.6 \%$ \\
\hline \multicolumn{11}{|l|}{ Currently Experiencing Menstruation ${ }^{1}$} \\
\hline Yes, self-reported regular menstruation & 750 & $53.3 \%$ & 302 & $88.8 \%$ & 189 & $59.1 \%$ & 254 & $64.3 \%$ & 5 & $1.4 \%$ \\
\hline Yes, self-reported irregular menstruation & 129 & $9.2 \%$ & 37 & $10.9 \%$ & 33 & $10.3 \%$ & 54 & $13.7 \%$ & 5 & $1.4 \%$ \\
\hline No, Pregnant & 76 & $5.4 \%$ & 1 & $0.3 \%$ & 65 & $20.3 \%$ & 10 & $2.5 \%$ & 0 & $0.0 \%$ \\
\hline No, Recently Gave Birth & 45 & $3.2 \%$ & 0 & $0.0 \%$ & 32 & $10.0 \%$ & 13 & $3.3 \%$ & 0 & $0.0 \%$ \\
\hline No, Menopause & 403 & $28.6 \%$ & 0 & $0.0 \%$ & 1 & $0.3 \%$ & 64 & $16.2 \%$ & 338 & $97.1 \%$ \\
\hline $\begin{array}{c}\text { Total Participants in } \\
\text { Menstruation Sub-Study }\end{array}$ & \multicolumn{2}{|c|}{878} & 338 & $38.5 \%$ & 222 & $25.3 \%$ & 308 & $35.1 \%$ & 10 & $1.1 \%$ \\
\hline Former Intervention Community & 436 & $49.7 \%$ & 165 & $48.8 \%$ & 104 & $46.8 \%$ & 159 & $51.6 \%$ & 8 & $80.0 \%$ \\
\hline Age & 26.80 & 7.68 & 21.22 & 2.95 & 24.01 & 3.06 & 34.09 & 6.05 & 52.70 & 4.00 \\
\hline Hindu & 866 & $98.6 \%$ & 336 & $99.4 \%$ & 219 & $98.6 \%$ & 301 & $97.7 \%$ & 10 & $100.0 \%$ \\
\hline Possession of Below Poverty Line (BPL) Card ${ }^{1}$ & 549 & $62.6 \%$ & 226 & $66.9 \%$ & 137 & $61.7 \%$ & 179 & $58.3 \%$ & 7 & $70.0 \%$ \\
\hline Have Children & 447 & $50.9 \%$ & 0 & $0.0 \%$ & 140 & $63.1 \%$ & 297 & $96.4 \%$ & 10 & $100.0 \%$ \\
\hline Mean Number of Children & 1.01 & 1.26 & 0 & 0 & 0.68 & 0.56 & 2.30 & 1.13 & 3.40 & 0.70 \\
\hline No Current Illness ${ }^{1}$ & 776 & $88.6 \%$ & 306 & $90.5 \%$ & 209 & $94.1 \%$ & 258 & $84.3 \%$ & 2 & $20.0 \%$ \\
\hline \multicolumn{11}{|l|}{ Caste } \\
\hline Brahmin & 26 & $3.0 \%$ & 10 & $3.0 \%$ & 7 & $3.2 \%$ & 9 & $2.9 \%$ & 0 & $0.0 \%$ \\
\hline General Caste & 392 & $44.7 \%$ & 149 & $44.1 \%$ & 104 & $47.1 \%$ & 135 & $43.8 \%$ & 4 & $40.0 \%$ \\
\hline Scheduled Caste (SC) & 158 & $18.0 \%$ & 51 & $15.1 \%$ & 43 & $19.5 \%$ & 62 & $20.1 \%$ & 2 & $20.0 \%$ \\
\hline Other Backward Caste (OBC) & 283 & $32.3 \%$ & 122 & $36.1 \%$ & 60 & $27.1 \%$ & 97 & $31.5 \%$ & 4 & $40.0 \%$ \\
\hline Scheduled Tribe (ST) & 5 & $0.6 \%$ & 2 & $0.6 \%$ & 2 & $0.9 \%$ & 1 & $0.3 \%$ & 0 & $0.0 \%$ \\
\hline Don't Know & 12 & $1.4 \%$ & 3 & $0.9 \%$ & 5 & $2.3 \%$ & 4 & $1.3 \%$ & 0 & $0.0 \%$ \\
\hline
\end{tabular}


Table 1. Cont.

\begin{tabular}{|c|c|c|c|c|c|c|c|c|c|c|}
\hline Characteristics & \multicolumn{2}{|c|}{ All } & \multicolumn{2}{|c|}{$\begin{array}{l}\text { 1. Unmarried } \\
\text { (UM) }\end{array}$} & \multicolumn{2}{|c|}{$\begin{array}{l}\text { 2. Recently Married } \\
\text { (RM) }\end{array}$} & \multicolumn{2}{|c|}{$\begin{array}{l}\text { 3. Married } \\
\text { (M) }\end{array}$} & \multicolumn{2}{|c|}{ 4. Over $49(\mathrm{OW})$} \\
\hline None & 69 & $7.9 \%$ & 3 & $0.9 \%$ & 6 & $2.7 \%$ & 55 & $17.9 \%$ & 5 & $50.0 \%$ \\
\hline Some Primary & 245 & $27.9 \%$ & 53 & $15.7 \%$ & 44 & $19.8 \%$ & 143 & $46.4 \%$ & 5 & $50.0 \%$ \\
\hline Some Secondary & 492 & $56.0 \%$ & 232 & $68.6 \%$ & 161 & $72.5 \%$ & 99 & $32.1 \%$ & 0 & $0.0 \%$ \\
\hline Higher than Secondary & 72 & $8.2 \%$ & 50 & $14.8 \%$ & 11 & $5.0 \%$ & 11 & $3.6 \%$ & 0 & $0.0 \%$ \\
\hline \multicolumn{11}{|l|}{$\begin{array}{c}\text { Absorbent Material } \\
\text { Used for Menstruation }^{1}\end{array}$} \\
\hline Reusable Cloth & 611 & $69.6 \%$ & 224 & $66.3 \%$ & 112 & $50.5 \%$ & 265 & $86.9 \%$ & 10 & $100.0 \%$ \\
\hline Disposable Pad & 204 & $23.2 \%$ & 83 & $24.6 \%$ & 89 & $40.1 \%$ & 31 & $10.2 \%$ & 0 & $0.0 \%$ \\
\hline Both Cloth and Pad & 61 & $6.9 \%$ & 31 & $9.2 \%$ & 21 & $9.5 \%$ & 9 & $3.0 \%$ & 0 & $0.0 \%$ \\
\hline \multicolumn{11}{|l|}{ Household Water and Sanitation Access } \\
\hline Functional Latrine in Household ${ }^{1}$ & 288 & $32.9 \%$ & 94 & $27.8 \%$ & 101 & $45.5 \%$ & 89 & $29.1 \%$ & 4 & $40.0 \%$ \\
\hline $\begin{array}{c}\text { Primary Drinking Water Source within } \\
\text { Dwelling/Compound }{ }^{2}\end{array}$ & 242 & $29.3 \%$ & 83 & $25.9 \%$ & 74 & $36.3 \%$ & 81 & $27.8 \%$ & 4 & $40.0 \%$ \\
\hline Bathing Room in Household ${ }^{1}$ & 131 & $15.1 \%$ & 26 & $7.7 \%$ & 66 & $29.9 \%$ & 38 & $12.5 \%$ & 1 & $10.0 \%$ \\
\hline
\end{tabular}

Data are number and percent or mean (and standard deviation). ${ }^{1}$ For Total Surveyed: 29 excluded because family member surveyed or under age 18; For Currently Experiencing Menstruation: 5 missing (stage 1 \& stage 4); For Caste: 2 missing (stage 1 \& stage 2) and 12 indicated don't know; For BPL Card: 1 missing (stage 3); For No Current Illness: 2 missing (stage 3); For Absorbent Material Used: 1 missing (stage 3); For Bathing Room in Household: 8 missing (stage 1, stage2, \& stage 3). ${ }^{2}$ For Primary Drinking Source: data taken from census, 53 missing (stage 1, stage 2, \& stage 3); For Functional Latrine in Household: data taken from census, 2 missing (stage 3). 


\subsubsection{Split Samples Created for Analysis}

Random splits resulted in 426 observations for EFA and 452 observations for CFA. T-tests to compare the groups revealed an even split, with comparable distributions in each group (See Supplemental Table S3 for split group demographics) and were deemed similar to obtain valid results for EFA and CFA. All but two menstruation module items had similar response distributions in the two groups; 'Had to stay separated at night from my normal bed' and 'Had to wear a cloth that was not fully dry after washing' had different response proportions between the groups (See Supplemental Table S5 for split group item response frequencies).

\subsection{Exploratory Factor Analysis}

The initial scree plot of the data indicated that a 7-factor structure may provide the best fit. Based on this information and our original hypothesis that there would be four factors linked to the identified themes, we assessed models from 4 to 10 factors to determine which was best-suited. We considered both model fit statistics and overall theoretical fit of the items to the factors. Using the Mplus 8.3 QUARTMIN rotation, we determined the 5 -factor solution provided the best balance between theoretical fit and model statistics. After iteratively dropping items based on factor loading values and cross-loadings, 19 of the 40 items were included in the final 5-factor scale, which explained $69 \%$ of the variance among those 19 items (above the 60\% threshold [53]) (See Supplemental Table S6 for reasons items were dropped). The model produced strong, positive loadings and had good model fit statistics (RMSEA $=0.027 ; \mathrm{CFI}=0.994 ; \mathrm{TLI}=0.989$; Table 3).

Based on the items within, we labeled the five factors: "Restrictions," "Management", "Symptoms," "Menstrual Cycle Concerns," and "Menstruation-Related Bodily Concerns" (referred to moving forward as 'Bodily Concerns' for ease). Factor 1 (Restrictions) includes two items about concerns continuing regular activities during menstruation (factor loadings: $0.866-0.998 ; 9.4 \%$ variance explained). Factor 2 (Management) contains nine items about women's concerns about their ability to access, wash, and store their chosen materials and care for themselves and their menstrual needs during menstruation (factor loadings: $0.482-0.932 ; 27.1 \%$ variance explained). Factor 3 (Symptoms) contains two items about physical symptoms experienced during menstruation (factor loadings: $0.847-0.883 ; 8.3 \%$ variance explained). Factor 4 (Menstrual Cycle Concerns) contains three items about women's concerns about their menstrual cycle or overall health related to their menstruation (factor loadings: $0.800-1.035 ; 12.7 \%$ variance explained). Finally, Factor 5 (Bodily Concerns) includes three items that address the concerns or experiences related to the body when using menstruation materials (factor loadings: 0.580-1.058; $11.6 \%$ variance explained). As hypothesized, the 'Management' and 'Restrictions' factors were retained. Our hypothesized 'Well-Being' factor essentially became two factors, Symptoms and Menstrual Cycle Concerns. The Bodily Concerns factor emerged to include items from three of the hypothesized factors.

Table 2. Responses frequencies for all Menstrual Insecurity items among women in rural Orissa, India, organized by factor analysis results and including deleted items $(n=878)$.

\begin{tabular}{lllll}
\hline & \multicolumn{3}{c}{ Full Sample (\%) } \\
\cline { 2 - 5 } & Never & Some-times & Often & Always \\
\hline \multicolumn{1}{c}{ Factor 1: Restrictions } \\
\hline $\begin{array}{c}\text { Could not touch certain things, which created difficulties for } \\
\text { me }\end{array}$ & $297(34)$ & $276(31)$ & $129(15)$ & $176(20)$ \\
Worry about not being able to participate in religious activities & $241(27)$ & $261(30)$ & $121(25)$ & $255(29)$ \\
\hline
\end{tabular}


Table 2. Cont

\begin{tabular}{|c|c|c|c|c|}
\hline & \multicolumn{4}{|c|}{ Full Sample (\%) } \\
\hline & Never & Some-times & Often & Always \\
\hline \multicolumn{5}{|c|}{ Factor 2: Management } \\
\hline $\begin{array}{l}\text { Had difficulty finding a place to change menstrual materials } \\
\text { (cloth or pad) }\end{array}$ & $804(92)$ & $35(4)$ & $15(2)$ & $24(3)$ \\
\hline Had difficulty finding a place to wash cloth & $717(82)$ & $51(6)$ & $40(5)$ & $70(8)$ \\
\hline Had difficulty finding a place to store menstrual cloth or pads & $819(93)$ & $30(3)$ & $9(1)$ & $20(2)$ \\
\hline Experienced difficulty bathing during menstruation & $676(77)$ & $103(12)$ & $43(5)$ & $56(6)$ \\
\hline Had difficulty finding a place to dispose of cloth or pad & $791(90)$ & $28(3)$ & $22(3)$ & $37(4)$ \\
\hline $\begin{array}{l}\text { Could not get the material I needed, like cotton cloth or } \\
\text { sanitary pad }\end{array}$ & $832(95)$ & $33(4)$ & $8(1)$ & $5(1)$ \\
\hline $\begin{array}{l}\text { Had difficulty finding a suitable place to dry my menstrual } \\
\text { cloth }\end{array}$ & $749(85)$ & $49(6)$ & $27(3)$ & $53(6)$ \\
\hline $\begin{array}{l}\text { Had difficulty finding someone to help me with bathing and } \\
\text { other menstruation-related needs at onset }\end{array}$ & $683(78)$ & $152(17)$ & $17(2)$ & $26(3)$ \\
\hline Had to stay separated at night from my normal bed & $762(87)$ & $69(8)$ & $13(1)$ & $34(4)$ \\
\hline \multicolumn{5}{|c|}{ Factor 3: Symptoms } \\
\hline Experienced pain in the hands or legs during menstruation & $329(37)$ & $174(20)$ & $134(15)$ & $241(27)$ \\
\hline Experienced stomach pains during menstruation & $340(39)$ & $179(20)$ & $105(12)$ & $254(29)$ \\
\hline \multicolumn{5}{|c|}{ Factor 4: Menstrual Cycle Concerns } \\
\hline Worried that my cycle was irregular & $798(91)$ & $26(3)$ & $10(1)$ & $44(5)$ \\
\hline $\begin{array}{l}\text { Worried about ability to become pregnant because of } \\
\text { problems with my menstrual cycle }\end{array}$ & $849(97)$ & $12(1)$ & $7(1)$ & $10(1)$ \\
\hline $\begin{array}{l}\text { Worried about my health because of problems with my } \\
\text { menstrual cycle }\end{array}$ & $790(90)$ & $44(5)$ & $12(1)$ & $32(4)$ \\
\hline \multicolumn{5}{|c|}{ Factor 5: Bodily Concerns } \\
\hline Got wounds on inner thighs from cloth or belt & $655(75)$ & $182(21)$ & $20(2)$ & $21(2)$ \\
\hline Worried that my cloth, napkin or my body smelled & $756(86)$ & $42(5)$ & $42(5)$ & $38(4)$ \\
\hline Had trouble doing my work because of wound from cloth/pad & $774(88)$ & $74(8)$ & $11(1)$ & $19(2)$ \\
\hline \multicolumn{5}{|c|}{ Items Deleted Based On Factor Analysis } \\
\hline Avoided leaving the house during menstruation & $470(54)$ & $53(6)$ & $162(18)$ & $193(22)$ \\
\hline Did not feel like eating during menstruation & $471(54)$ & $227(26)$ & $77(9)$ & $103(12)$ \\
\hline $\begin{array}{c}\text { Worried about needing other's support to get the cloth or } \\
\text { sanitary pads I needed }\end{array}$ & $688(78)$ & $140(16)$ & $25(3)$ & $25(3)$ \\
\hline Experienced headache during menstruation & $693(79)$ & $114(13)$ & $33(4)$ & $38(4)$ \\
\hline Did not feel like interacting with others during menstruation & $668(76)$ & $112(13)$ & $33(4)$ & $65(7)$ \\
\hline $\begin{array}{l}\text { Experienced burning and irritation in urinary tract during } \\
\text { menstruation }\end{array}$ & $683(78)$ & $131(15)$ & $36(4)$ & $28(3)$ \\
\hline Got blood stains or leaks on my clothes & $755(86)$ & $106(12)$ & $11(1)$ & $6(1)$ \\
\hline Experienced heavy bleeding & $712(81)$ & $98(11)$ & $34(4)$ & $34(4)$ \\
\hline Felt like vomiting during menstruation & $779(89)$ & $50(6)$ & $19(2)$ & $30(3)$ \\
\hline Had a lot of cleaning work to do because of menstruation & $627(71)$ & $87(10)$ & $113(13)$ & $51(6)$ \\
\hline Had difficulty doing my regular work during menstruation & $506(58)$ & $190(22)$ & $105(12)$ & $77(9)$ \\
\hline Had difficulty fetching water for menstruation related needs & $556(63)$ & $143(16)$ & $88(10)$ & $91(10)$ \\
\hline Had difficulty urinating while menstruating & $627(71)$ & $147(17)$ & $50(6)$ & $54(6)$ \\
\hline Had difficulty walking during menstruation & $508(58)$ & $230(26)$ & $53(6)$ & $87(10)$ \\
\hline Was forced to conform to a restriction that I do not believe in & $729(83)$ & $117(13)$ & $9(1)$ & $23(3)$ \\
\hline Had people tease me because they knew I was menstruating & $865(99)$ & $11(1)$ & $1(0)$ & $1(0)$ \\
\hline Worried about being treated as untouchable by others & $832(95)$ & $26(3)$ & $6(1)$ & $14(2)$ \\
\hline Had to wear cloth that was not fully dry after washing * & 847 (97) & $26(3)$ & $4(0)$ & $0(0)$ \\
\hline Have a general feeling of tension at onset of menstruation & $307(35)$ & $139(16)$ & $180(21)$ & $252(29)$ \\
\hline Was prevented from going to certain places that I wanted to go & $666(76)$ & $110(13)$ & $11(1)$ & $91(10)$ \\
\hline Worried that others knew I was menstruating & $862(98)$ & $9(1)$ & $3(0)$ & $4(0)$ \\
\hline
\end{tabular}

* 1 participant missing (Sub-sample $\mathrm{n}_{2}=451$ ). 
Table 3. Final factor loadings and model fit statistics for random split-half sample EFA $(\mathrm{N} 1=426)$ and CFA models (N2 $=452)$.

\begin{tabular}{|c|c|c|c|}
\hline Model & $\begin{array}{l}\text { Item } \\
\text { Code }\end{array}$ & $\begin{array}{c}\text { EFA } \\
\left(N_{1}=426\right)\end{array}$ & $\begin{array}{c}\mathrm{CFA}^{1} \\
\left(\mathrm{~N}_{2}=452\right)\end{array}$ \\
\hline \multicolumn{4}{|l|}{ Factor 1: Restrictions } \\
\hline Could not touch certain things, which created difficulties for me & M14 & 0.866 & $0.847 *$ \\
\hline Worry about not being able to participate in religious activities & M13 & 0.998 & $0.975 *$ \\
\hline \multicolumn{4}{|l|}{ Factor 2: Management } \\
\hline Had difficulty finding a place to change menstrual materials (cloth or pad) & M29 & 0.836 & $0.911 *$ \\
\hline Had difficulty finding a place to wash cloth & M21 & 0.931 & $0.908 *$ \\
\hline Had difficulty finding a place to store menstrual cloth or pads & M39 & 0.813 & $0.826 *$ \\
\hline Experienced difficulty bathing during menstruation & M19 & 0.672 & $0.787 *$ \\
\hline Had difficulty finding a place to dispose of cloth or pad & M33 & 0.820 & $0.736 *$ \\
\hline Could not get the material I needed, like cotton cloth or sanitary pad & M11 & 0.606 & $0.485 *$ \\
\hline Had difficulty finding a suitable place to dry my menstrual cloth & M25 & 0.932 & $0.763 *$ \\
\hline $\begin{array}{l}\text { Had difficulty finding someone to help me with bathing and other } \\
\text { menstruation-related needs at onset }\end{array}$ & M38 & 0.645 & $0.629 *$ \\
\hline Had to stay separated at night from my normal bed & M40 & 0.482 & $0.326 *$ \\
\hline \multicolumn{4}{|l|}{ Factor 3: Symptoms } \\
\hline Experienced pain in the hands or legs during menstruation & M23 & 0.883 & $1.074^{*}$ \\
\hline Experienced stomach pains during menstruation & M24 & 0.847 & $0.689 *$ \\
\hline \multicolumn{4}{|l|}{ Factor 4: Menstrual Cycle Concerns } \\
\hline Worried that my cycle was irregular & M37 & 1.035 & $0.835 *$ \\
\hline $\begin{array}{l}\text { Worried about ability to become pregnant because of problems with my } \\
\text { menstrual cycle }\end{array}$ & M47 & 0.815 & $0.852 *$ \\
\hline Worried about my health because of problems with my menstrual cycle & M41 & 0.800 & $0.871 *$ \\
\hline \multicolumn{4}{|l|}{ Factor 5: Bodily Concerns } \\
\hline Got wounds on inner thighs from cloth or belt & M28 & 0.808 & $0.628 *$ \\
\hline Worried that my cloth, napkin or my body smelled & M48 & 0.580 & 0.401 * \\
\hline Had trouble doing my work because of wound from cloth/pad & M44 & 1.058 & $1.315 *$ \\
\hline \multicolumn{4}{|l|}{ Model Fit Statistics } \\
\hline RMSEA & & 0.027 & 0.058 \\
\hline CFI & & 0.994 & 0.937 \\
\hline TLI & & 0.989 & 0.925 \\
\hline
\end{tabular}

${ }^{1}$ CFA Factor Loadings standardized using STDYX Standardization in MPLUS; ${ }^{*} p \leq 0.01$.

\subsection{Confirmatory Factor Analysis}

All items loaded in the CFA in similar ranges as for the EFA and were significant (Table 3). No additional items were dropped. The model fit statistics provided satisfactory evidence that the factor structure was appropriate for the data $(\mathrm{RMSEA}=0.058 ; \mathrm{CFI}=0.937 ; \mathrm{TLI}=0.925)$. Hierarchical CFA confirmed that all sub-scales form a unidimensional scale, and that a total score can be used to assess menstrual insecurity (RMSEA $=0.057 ; \mathrm{CFI}=0.936$; TLI $=0.926$; See Supplemental Figure S2 for Hierarchical CFA Model Diagram). Additionally, bifactor CFA models with and without factor 3 were used to confirm its psychometric relevance to the overall factor structure, despite having the lowest factor variance in EFA.

\subsection{Reliability and Validity Analyses}

\subsubsection{Reliability Analysis}

Cronbach's alpha for the full 19-item scale was 0.75, which exceeds the threshold for acceptable internal consistency-reliability (Table 4). The items within each factor indicated moderate to high internal consistency based on the alpha values of each individual factor (0.63-0.86). All factors had low to moderate inter-correlations, reiterating that each factor is representing a related, but distinct component of Menstrual Insecurity. 
Table 4. Scale and Factor descriptive characteristics, inter-correlations, and internal consistency reliability.

\begin{tabular}{|c|c|c|c|c|c|c|c|c|}
\hline & \multirow{2}{*}{$\begin{array}{l}\text { No. of } \\
\text { Items }\end{array}$} & \multirow{2}{*}{$\begin{array}{l}\text { Mean Score } \\
\text { (SD) }\end{array}$} & \multicolumn{5}{|c|}{ Correlations between Scale Factors } & \multirow{2}{*}{$\begin{array}{c}\text { Internal Consistency } \\
\text { Reliability }^{1}\end{array}$} \\
\hline & & & F1 & F2 & F3 & F4 & F5 & \\
\hline Total Score & 19 & $1.46(0.34)$ & $0.57^{*}$ & $0.79 *$ & $0.55 *$ & $0.36 *$ & $0.38 *$ & 0.75 \\
\hline F1: Restrictions & 2 & $2.33(1.07)$ & & $0.23 *$ & $0.16 *$ & 0.05 & $0.16 *$ & 0.86 \\
\hline F2: Management & 9 & $1.24(0.42)$ & & & 0.20 * & 0.13 * & $0.13 *$ & 0.80 \\
\hline F3: Symptoms & 2 & $2.32(1.12)$ & & & & 0.13 * & 0.03 & 0.77 \\
\hline $\begin{array}{l}\text { F4: Menstrual } \\
\text { Cycle Concerns }\end{array}$ & 3 & $1.15(0.46)$ & & & & & 0.05 & 0.69 \\
\hline $\begin{array}{l}\text { F5: Bodily } \\
\text { Concerns }\end{array}$ & 3 & $1.26(0.49)$ & & & & & & 0.63 \\
\hline
\end{tabular}

\subsubsection{Validity}

All factors were significantly associated with many thematically similar survey items (See Supplemental Table S7 for items used for validation). The Restrictions factor was correlated with women's ability to travel alone to locations outside of the village, the place where they defecate, and the place where they urinate $(p s<0.005)$. The Management factor was correlated with difficulty finding a private place to urinate and having an enclosed household bathing area $(p s<0.0001)$. The Symptoms factor was associated with having vaginal discharge, burning or itching while urinating, and burning or itching in the vaginal area in the previous two weeks ( $p s<0.0001)$. The Menstrual Cycle Concerns factor was associated with self-reports of currently experiencing regular versus irregular menstruation $(p<0.0001)$ and the Bodily Concerns factor was associated with reusing absorbent material (vs. throwing away) $(p<0.005)$. Additionally, discriminant validity of the Bodily Concerns factor is supported by known-group validity. The score was significantly higher $(t=2.19, p<0.05)$ among those who reported burning or itching in the vaginal area $(n=107)$ than among those who did $\operatorname{not}(n=769)$.

\subsubsection{Menstrual Insecurity Scores}

The mean total Menstrual Insecurity score was 1.46; scores were significantly higher (indicating greater insecurity) among those with no functional household latrine, no enclosed household bathing area, no within compound water source, and among those using reusable cloth materials.

Women who reported at least sometimes experiencing tension at menstrual onset had significantly higher Menstrual Insecurity scores than women who reported never experiencing tension (1.30). Those indicating they always experienced tension at menstrual onset reported the highest scores for Menstrual Insecurity overall (1.63), and for four of the five factors. Women who reported at least sometimes experiencing difficulty doing their regular work during menstruation had significantly higher Menstrual Insecurity scores than women who reported never having difficulty. Those indicating they always experienced difficulty reported the highest scores for Menstrual Insecurity overall (1.93), and for each of the five factors.

Mean scores for the full sample ranged from 1.15 (Factor 4: Menstrual Cycle Concerns) to 2.33 (Factor 1: Restrictions and Factor 3: Symptoms) (See Table 5 for Scores and Supplemental Table S8 for Weighted Scores). While there was no difference in overall scores by life stage, differences did exist for select factors. Specifically, recently married women and married women had significantly higher scores for restrictions ( $\mathrm{RM}=2.38 ; \mathrm{M}=2.55$ ) compared to unmarried women ( $\mathrm{UM}=2.07$ ), and married women had a significantly lower score for symptoms $(\mathrm{M}=2.11)$ compared to unmarried women $(\mathrm{UM}=2.46)$. 
Table 5. Overall Menstrual Insecurity and individual sub-scale scores by life stage-, WASH-, and health-related items $(\mathrm{N}=878)$.

\begin{tabular}{|c|c|c|c|c|c|c|}
\hline Characteristics & $\begin{array}{l}\text { Overall Menstrual } \\
\text { Insecurity }\end{array}$ & Factor 1: Restrictions & $\begin{array}{c}\text { Factor 2: } \\
\text { Management }\end{array}$ & Factor 3: Symptoms & $\begin{array}{l}\text { Factor 4: Menstrual } \\
\text { Cycle Concerns }\end{array}$ & $\begin{array}{l}\text { Factor 5: Bodily } \\
\text { Concerns }\end{array}$ \\
\hline All & $1.46(0.34)$ & $2.32(1.07)$ & $1.24(0.42)$ & $2.32(1.12)$ & $1.15(0.46)$ & $1.26(0.49)$ \\
\hline \multicolumn{7}{|l|}{ Life Stage } \\
\hline Unmarried Women (Ref.) & $1.45(0.34)$ & $2.07(0.99)$ & $1.24(0.41)$ & $2.46(1.12)$ & $1.14(0.43)$ & $1.27(0.51)$ \\
\hline Recently Married Women & $1.49(0.38)$ & $2.38(1.06) *$ & $1.27(0.49)$ & $2.42(1.17)$ & $1.18(0.51)$ & $1.21(0.47)$ \\
\hline Married Women & $1.44(0.32)$ & $2.55(1.11) *$ & $1.21(0.39)$ & $2.11(1.06) *$ & $1.13(0.45)$ & $1.28(0.49)$ \\
\hline Older Women & $1.44(0.23)$ & $2.70(1.16)$ & $1.17(0.28)$ & $1.95(1.23)$ & $1.27(0.64)$ & $1.27(0.49)$ \\
\hline \multicolumn{7}{|l|}{ Own Functional Latrine } \\
\hline Owns (Ref.) & $1.38(0.28)$ & $2.19(1.05)$ & $1.14(0.30)$ & $2.28(1.09)$ & $1.13(0.43)$ & $1.22(0.46)$ \\
\hline Does Not Own & $1.49(0.36)^{*}$ & $2.40(1.08)^{*}$ & $1.29(0.46)^{*}$ & $2.34(1.14)$ & $1.16(0.47)$ & $1.27(0.51)$ \\
\hline \multicolumn{7}{|l|}{ Enclosed Bathing Area ${ }^{1}$} \\
\hline Owns (Ref.) & $1.34(0.25)$ & $2.14(1.04)$ & $1.08(0.21)$ & $2.32(1.14)$ & $1.09(0.36)$ & $1.18(0.45)$ \\
\hline Does Not Own & $1.48(0.35)^{*}$ & $2.36(1.08) *$ & $1.27(0.45)^{*}$ & $2.32(1.12)$ & $1.16(0.47)$ & $1.27(0.50)$ \\
\hline \multicolumn{7}{|l|}{ Water Source $^{1}$} \\
\hline Inside Compound (Ref.) & $1.39(0.27)$ & $2.29(1.06)$ & $1.12(0.26)$ & $2.38(1.12)$ & $1.11(0.40)$ & $1.24(0.49)$ \\
\hline Outside Compound & $1.48(0.36)^{*}$ & $2.35(1.10)$ & $1.29(0.46)^{*}$ & $2.30(1.12)$ & $1.16(0.48)$ & $1.26(0.50)$ \\
\hline \multicolumn{7}{|l|}{ Menstruation Materials $^{2}$} \\
\hline Reusable Cloth (Ref.) & $1.47(0.34)$ & $2.37(1.08)$ & $1.25(0.42)$ & $2.27(1.11)$ & $1.17(0.49)$ & $1.30(0.53)$ \\
\hline Disposable Pad & $1.40(0.29) *$ & $2.22(1.02)$ & $1.17(0.35)^{*}$ & $2.45(1.17)$ & $1.09(0.31) *$ & $1.17(0.40) *$ \\
\hline Both Pad and Cloth & $1.54(0.44)$ & $2.34(1.11)$ & $1.40(0.60)$ & $2.43(1.08)$ & $1.21(0.57)$ & $1.16(0.35) *$ \\
\hline Nothing & $1.05(0.07)$ & $1.00(0.00)^{*}$ & $1.00(0.00)^{*}$ & $1.25(0.35)$ & $1.17(0.24)$ & $1.00(0.00)$ * \\
\hline \multicolumn{7}{|l|}{$\begin{array}{c}\text { Tension at Menstruation } \\
\text { Onset }\end{array}$} \\
\hline Never (Ref.) & $1.30(0.25)$ & $2.00(0.96)$ & $1.12(0.27)$ & $2.01(1.05)$ & $1.13(0.39)$ & $1.10(0.21)$ \\
\hline Sometimes & $1.47(0.32) *$ & $2.17(0.88)$ & $1.28(0.43)^{*}$ & $2.35(1.08) *$ & $1.23(0.55)$ & $1.24(0.37) *$ \\
\hline Often & $1.46(0.26)^{*}$ & $2.36(0.92) *$ & $1.22(0.32) *$ & $2.25(1.01) *$ & $1.08(0.31)$ & $1.45(0.58)$ * \\
\hline Always & $1.63(0.41)$ * & $2.78(1.23)$ * & $1.39(0.57)^{*}$ & $2.73(1.18) *$ & $1.18(0.56)$ & $1.32(0.65) *$ \\
\hline \multicolumn{7}{|c|}{ Had Difficulty Doing My Regular Work During Menstruation } \\
\hline Never (Ref.) & $1.35(0.27)$ & $2.12(1.03)$ & $1.14(0.29)$ & $2.19(1.12)$ & $1.12(0.39)$ & $1.15(0.35)$ \\
\hline Sometimes & $1.47(0.29) *$ & $2.31(0.91)^{*}$ & $1.27(0.40)^{*}$ & $2.33(1.03)$ & $1.15(0.49)$ & $1.29(0.46) *$ \\
\hline Often & $1.58(0.27) *$ & $2.86(1.00) *$ & $1.28(0.36) *$ & $2.32(1.11)$ & $1.15(0.45)$ & $1.57(0.71) *$ \\
\hline Always & $1.93(0.49) *$ & $3.04(1.24) *$ & $1.79(0.75) *$ & $3.10(1.05)^{*}$ & $1.34(0.70) *$ & $1.44(0.74) *$ \\
\hline
\end{tabular}

${ }^{1}$ For Enclosed Bathing Area: 8 missing; For Water Source: 53 participants missing. ${ }^{2}$ For Menstruation Materials: 1 participant missing, 611 Reusable Cloth, 203 Disposable Pad, 61 Both, 2 None; ${ }^{*} p$-value $<0.05$. 
Women who did not own a functional household latrine had higher scores across all five factors compared to women who did; scores were significantly higher for the restrictions (2.40) and management factors (1.29). Women who did not own an enclosed bathing area in their household had higher scores for four factors compared to women who did; scores were significantly higher for the restrictions (2.36) and management factors (1.27). Women who did not have a water source within their household compound had higher scores across four factors compared to women who had their water source outside the compound; scores were significantly higher for the management factor (1.29). Women who used a disposable pad during menstruation had significantly lower scores across four of the five factors compared to women who only used a reusable cloth; scores were significantly lower for the Management (1.17), Menstrual Cycle Concerns (1.09), and Bodily Concerns (1.17) factors.

\section{Discussion}

We used a rigorous, mixed methods approach to create and validate a culturally-grounded measure of Menstrual Insecurity, which we defined preliminarily as 'the suite of social, environmental, and biological concerns and negative experiences resulting from menstruation'. The measure was designed to reflect the menstruation-related concerns and negative experiences of women from rural Odisha, India, and to assess the frequency of those concerns and negative experiences among a representative sample. Through our qualitative phase, we identified four themes that we hypothesized would emerge as factors that reflect conditions of women's social and physical environments, and their individual experiences of menstruation, extending beyond but including management. Five factors emerged that deviate slightly from the four hypothesized, but are theoretically plausible and do reflect the social environment (Restrictions), the social and physical environment collectively (Management), and individual experience (Symptoms; Menstrual Cycle Concerns; Bodily Concerns) as noted in the definition. The measure is internally consistent, and sub-scale scores were significantly associated with thematically similar survey items, demonstrating validity. Post-hoc exploration of Menstrual Insecurity scores were highest among those reporting tension at menstrual onset or difficulty doing regular work during menstruation, and suggest the need for further research.

Our post-hoc finding that those experiencing tension at menstrual onset had significantly higher Menstrual Insecurity scores is consistent with qualitative studies [8,54-56]. For clarity, in this context tension is understood to be distress about menstruation, not emotional variations due to hormones, similar to what has been described by Weaver (2017) [57]. A pair of research studies with women in rural, urban, and tribal areas of Odisha identified menstruation to be a stressful sanitation-related activity [10] and the activity most likely to be ranked 'most stressful' [11]. The present research moves beyond the sanitation-specific lens to include aspects of menstruation beyond management. Items included in the final measure ask about restrictions, pain, and overall concerns about the menstrual cycle, among others, which have been noted to be under documented in current research, including in the foundational definition of menstrual hygiene management $[23,58]$. In our study, women reporting tension at menstrual onset had significantly higher Menstrual Insecurity scores overall, and for select sub-scales, suggesting the importance of these menstruation experiences and the need for further research exploring the relationship between the varied menstruation experiences and validated mental health outcomes.

We found that those who reported difficulty doing regular work during menstruation had significantly higher overall Menstrual Insecurity and individual sub-scale scores than those reporting they never faced difficulties. Research on menstruation and work is limited [59]. The highest scores reported were for the Symptoms and Restrictions factors, potential priority areas for future research and programming. We intentionally left our question open, allowing women to consider 'regular work' in their context, whether unpaid in the home or for income generation. Still, our analysis is limited to known groups and further research is needed to understand how menstruation impacts work, what types of work are impacted, the consequences of having difficulty engaging work, and what can be done to ameliorate menstruation-related work challenges. 
There has been limited research focus on menstrual discomfort and pain, including impacts on menstruator's lives, and amelioration strategies $[23,58]$. Our Symptoms and Bodily Concerns factors both address the bodily experience of menstruation; the Symptoms factor focuses on pain attributable to the menstrual cycle and the Bodily Concerns factor reflects women's concerns about the body related to management, including wounds and smell. Ignoring pain is not new; research has documented how women's reports of pain and discomfort for other health ailments have been disregarded and untreated [60]. Our research shows that menstrual pain and discomfort are a concern for women, associated with feelings of tension and difficulty working, can be from different causes (cycle or management), and need attention.

While the Symptoms and Bodily Concerns sub-scales do provide some insight, they also have limitations. The symptoms factor only has two items, limiting its comprehensiveness, and does not enable assessment of whether or not these symptoms are concerning for women, but just the frequency of occurrence. In future work, we would aim to revise this sub-scale by specifically asking women if they were concerned about a more expansive list of symptoms. Further, we think it also would be useful to test a culturally appropriate 'Menstruation Symptoms Index' to accompany this sub-scale. The index could be used to determine which, of a range of symptoms, women experience, and how intense the symptoms are. Some older measures do exist, and these would need testing to assure contextual appropriateness [61,62]. Similarly, we would revise items in the Bodily Concerns sub-scale to more explicitly assess worry or challenges related to the body as a result of management, rather than simply asking about an experience (e.g., concern about wounds from cloth).

Women who reported always having difficulty working during menstruation or feeling tension at menstrual onset had high restrictions scores, highlighting the need for further research to understand how menstruation-related restrictions impact menstruator's lives. Van Eijk et al.'s systematic review of menstruation among girls in India noted myriad restrictions [63], and in their research on girls' menstruation and schooling in Bangladesh, Alam et al. found school absence to be more common among girls who faced restrictions during menstruation. This factor needs further development and is likely to be quite varied contextually.

Women had significantly higher scores for Management if they lacked access to enabling WASH environments or used reusable cloth. Our quantitative findings that women have greater difficulty managing menstruation when they have limited WASH and absorbent material access are consistent with numerous qualitative studies that have amplified women's and girls' voiced challenges managing menstruation in schools and at home $[10,12,22,64-66]$. In this factor, one item may seem like an outlier (Had to stay separated at night from my normal bed). However, in the qualitative work women described sleeping out of their beds before and during menstruation not because of any restriction, but to avoid having to wash bed linens, and is therefore management-related. In our study, women had limited access to functional latrine facilities (33\%), enclosed bathing spaces $(15 \%)$, water sources within their compounds (29\%), and disposable pads (23\%). Despite better scores among those with WASH access, only a limited number of women used WASH facilities for changing ( $3 \%$ in latrine; $6 \%$ in bathing space) or washing reusable materials ( $4 \%$ in latrine; $4 \%$ in bathing space). Thus, access to functional WASH facilities are clearly of use to some women, but only among a minority. The majority of women changed in the house $(89 \%)$ and used a pond or river for washing $(71 \%)$ and disposing $(66 \%)$ of materials. Other studies with women in India and Nigeria found access to and use of sanitation facilities for changing to be higher [24,40]. Low latrine use for menstrual needs among this rural Indian population is likely related to the well-documented aversion to using latrines even for urination and defecation $[10,22,67,68]$ and because facilities are not designed to be 'female friendly' [69]. While women using pads do not have to find places to wash and dry materials, they struggle with how and where to privately dispose [12]. Our research found that almost all women in our sample were disposing materials directly into the environment. Urgent attention to environmentally-forward material and disposal solutions are needed, particularly as global markets and subsidies for disposables continue to grow $[70,71]$. 
The Menstrual Cycle Concerns sub-scale highlights the need women have for information about the menstrual cycle and their own health. In the preceding qualitative research, participants asked research assistants if something was wrong with their health if their menstruation came on different dates each month [12]. That women were asking RAs about their cycles demonstrates that women have few sources of information about menstruation or health. Many studies have concluded that girls need to understand the basic biology of menstruation and links to reproduction [8,72], but it is clear that women also need information. Women's access to accurate information can benefit their own lives and also girls. Women are the mothers, sisters, grandmothers, and aunts who provide menstruation information to adolescents [72]. Women who have access to disposable pads had significantly lower scores for the Menstrual Cycle Concerns sub-scale. It may be that those with access to disposable products may also have better access to other resources, like health care or information (booklets with menstruation information are often provided in packages of commercial menstrual products) and thus do not have as many unanswered questions or concerns as those not using pads regularly.

All the retained items in the Menstrual Cycle Concerns sub-scale had over $90 \%$ of women respond that they 'never' had the concern or experience. Comparatively, $27 \%$ of qualitative participants perceived irregular menstruation to be a concern for women in general [22]. While a high proportion of 'never' responses for these and other items may seem at odds with our qualitative work, which showed higher endorsement, differences were expected. The current measure assesses concerns at the individual level, whereas the qualitative work asked about perceived concerns among women in the community in general, a deliberate approach used to capture a range of perceived concerns and to enable participants to feel more comfortable talking about challenging topics. Our quantitative assessment demonstrates that, though concerns or experiences may be widely recognized qualitatively in a community, many are not or are infrequently experienced at an individual level, further highlighting the value of mixed methods assessments.

Similarly, for four items in the management factor, $90 \%$ or more of respondents indicated that they 'never' had the concern. Each of the four items queried about cloth or pads, specifically difficulty in accessing materials needed, or difficulty finding a place to dispose, change, or store materials. Given that a high proportion (70\%) of the sample reported using reusable materials, it is not surprising that disposal was never an issue for $90 \%$ of respondents. For the other items, we simply asked about difficulty in accessing materials needed or in finding places for changing and storing in general. These items may have been too broad, too general. In the qualitative work, women discussed not being able to get materials they preferred or changing or storing materials in places they felt were not ideal. In future iterations of the scale, we would recommend refining these items to ask about perceived suitability of the materials accessed or places used for management. Women are resilient and will find a means to address their needs, but they may not do so in a manner that aligns with their preferences.

Finally, a number of items were not retained in our measure (See Supplemental Table S6), however many provide insightful information and can be used in future research even if not in the scale. Notably, during menstruation, many women experienced constrained mobility ( $24 \%$ were prevented from going to places they wanted to go to and $46 \%$ avoided leaving the house during menstruation), had difficulty accessing resources ( $37 \%$ had trouble fetching water), and had challenges meeting basic needs ( $29 \%$ had difficulty urinating).

\section{Strengths and Limitations}

A strength of this research is the ground-up approach. Items emerged from qualitative work with rural Indian women of varied life stages, allowing their voices to shape the measure, and leading to a scale with factors that represent their concerns. We would have liked to conduct cognitive interviews with women to enable additional feedback, however resources were constrained and we were unable to do so. However, we did carry out a careful review process with the enumerator team members, who are from similar villages as the participants, which provided some additional insights regarding translation. The ground-up approach is also a limitation. Some items may not be relevant in other 
contexts and the concerns of women in other settings may not be represented. However, the factors, and many items, align with menstruators' experiences across settings. Testing the scale, or even specific factors, in other settings and with other populations is needed. Additionally, our scale identified factors important to the menstruation experience beyond management. Two factors, Restrictions and Symptoms, have only two items and future work should develop these factors. It may be useful for each of these factors to be developed further as independent scales, depending on context, what may be of greatest utility to researchers and practitioners, and future learning in the field.

Due to constrained time and resources, we were not able to return to a subsample of participants to re-administer the survey and assess test-re-test reliability, nor were we able to carry out data collection at varied time points to assess predictive validity. Given that there are no comparable measures, we also were not able to assess criterion validity.

Finally, as research on menstruation evolves, the definition of Menstrual Insecurity, which is currently broad, may also evolve. Any future development of Menstrual Insecurity as a concept will have implications for the content validity of the current measure. In other words, the current items and sub-scales may not fully represent a future iteration of Menstrual Insecurity. Still, we consider this work and this measure to be a starting point and accept that the concept may evolve and that the measure may need to evolve as well. Indeed, concepts of food and water insecurity have changed over time, and so too have their measures, and those fields have benefited from those evolutions.

\section{Conclusions}

We created and validated a scale to measure Menstrual Insecurity, employing a rigorous, mixed-methods approach to reflect the concerns of women in rural Odisha India. The scale includes Management, Restrictions, Symptoms, Bodily Concerns, and Menstrual Cycle Concerns sub-scales, broadening what has to date been measured in menstruation-related research. We found that women who reported experiencing tension at menstrual onset and difficulty doing regular work to have higher Menstrual Insecurity scores. This measure may be used to identify needs for program planning. Future work can explore if there is an association between Menstrual Insecurity and health outcomes.

Supplementary Materials: The following are available online at http://www.mdpi.com/1660-4601/17/10/3468/ s1, Figure S1: Flow diagram illustrating community and individual eligibility, exclusion, non-participation, and inclusion in EFA/CFA, Figure S2: Diagram of Hierarchical Confirmatory Factor Analysis Model, Table S1: Survey Items Grouped by Four Emergent Themes and Post-EFA/CFA Results, Table S2: Menstrual Insecurity Item frequencies among women in rural Orissa, India $(n=878)$, Table S3: Demographic characteristics of survey participants, overall and by random split halves, in rural Orissa, India $(N=878)$, Table S4: Participant menstruation practices, overall and by life stage, in rural Orissa, India $(n=878)$, Table S5: Menstrual Insecurity item frequencies among women in rural Orissa, India, by random split half $(n=878)$, Table S6: Removed scale items with reasons for removal, Table S7: Items used for validation of scale, Table S8: Average weighted Menstrual Insecurity sub-scale scores by life stage-, health-, and sanitation-related items $(N=878)$.

Author Contributions: Conceptualization, B.A.C.; Data curation, B.A.C. and G.P.; Formal analysis, G.P. and S.M.; Funding acquisition, B.A.C. and T.C.; Investigation, B.A.C.; Methodology, B.A.C., S.M. and T.C.; Project administration, B.A.C.; Supervision, B.A.C.; Visualization, G.P.; Writing-original draft, B.A.C. and G.P.; Writing-review \& editing, S.M. and T.C. All authors have read and agreed to the published version of the manuscript.

Funding: This research was funded by the Bill \& Melinda Gates Foundation (BMGF) (OPP1125067). BMGF provides funding for open access publication.

Acknowledgments: The authors wish to thank the women who participated in this research and members of the research team: Parimita Routray, Puspa Barik, Rajani Barik, Sasmita Barik, Munmun Dasmohapatra, Sucheta Das Mohapatra, Sujata Dehury, Archana Harichandan, Arnapurna Harichandan Sadasiva Kothia, Alfred Mohanty, Rajashree Nayak, Soumya Nayak, Amrita Pattnaik, Sunita Ray, Manaswini Rout, Sonam Sahoo, Swarnalata Sahoo, Indrajit Samal, and Belen Torondel. We also thank Hannah L.F. Cooper, Craig Hadey, Regine H Haardöerfer, and Kathryn Yount who informed the parent research study from which data from this research originated.

Conflicts of Interest: The authors declare no conflict of interest. The funders had no role in the design of the study; in the collection, analyses, or interpretation of data; in the writing of the manuscript, or in the decision to publish the results. 


\section{Appendix A}

The original Menstrual Insecurity tool is provided for adaptation and utilization. Items not included in the final scale are marked as 'deleted' in the factor column.

Table A1. Menstrual Insecurity tool.

\begin{tabular}{|c|c|c|c|c|c|c|}
\hline \multicolumn{7}{|c|}{ How Often Have You Experienced Any of the Following during Your Last Two Menstrual Periods? } \\
\hline Factor & Item No. & Item & Never & Some-Times & Often & Always \\
\hline Deleted & M10 & $\begin{array}{l}\text { Avoided leaving the house during } \\
\text { menstruation }\end{array}$ & 01 & 02 & 03 & 04 \\
\hline F2 & M11 & $\begin{array}{l}\text { Could not get the material needed, like } \\
\text { cotton cloth or sanitary pad }\end{array}$ & 01 & 02 & 03 & 04 \\
\hline Deleted & M12 & $\begin{array}{l}\text { Did not feel like eating during } \\
\text { menstruation }\end{array}$ & 01 & 02 & 03 & 04 \\
\hline $\mathrm{F} 1$ & M13 & $\begin{array}{l}\text { Worry about not being able to participate } \\
\text { in religious activities }\end{array}$ & 01 & 02 & 03 & 04 \\
\hline F1 & M14 & $\begin{array}{l}\text { Could not touch certain things, which } \\
\text { created difficulties for me }\end{array}$ & 01 & 02 & 03 & 04 \\
\hline Deleted & M15 & $\begin{array}{l}\text { Worried about needing other's support } \\
\text { to get the cloth or sanitary pads I needed }\end{array}$ & 01 & 02 & 03 & 04 \\
\hline Deleted & M16 & $\begin{array}{c}\text { Experienced headache during } \\
\text { menstruation }\end{array}$ & 01 & 02 & 03 & 04 \\
\hline Deleted & M17 & $\begin{array}{l}\text { Did not feel like interacting with others } \\
\text { during menstruation }\end{array}$ & 01 & 02 & 03 & 04 \\
\hline Deleted & M18 & $\begin{array}{l}\text { Experienced burning and irritation in } \\
\text { urinary tract during menstruation }\end{array}$ & 01 & 02 & 03 & 04 \\
\hline F2 & M19 & $\begin{array}{c}\text { Experienced difficulty bathing during } \\
\text { menstruation }\end{array}$ & 01 & 02 & 03 & 04 \\
\hline Deleted & M20 & Got blood stains or leaks on my clothes & 01 & 02 & 03 & 04 \\
\hline F2 & M21 & $\begin{array}{l}\text { Had difficulty finding a place to wash } \\
\text { cloth }\end{array}$ & 01 & 02 & 03 & 04 \\
\hline Deleted & M22 & Experienced heavy bleeding & 01 & 02 & 03 & 04 \\
\hline F3 & M23 & $\begin{array}{l}\text { Experienced pain in the hands or legs } \\
\text { during menstruation }\end{array}$ & 01 & 02 & 03 & 04 \\
\hline F3 & M24 & $\begin{array}{c}\text { Experienced stomach pains during } \\
\text { menstruation }\end{array}$ & 01 & 02 & 03 & 04 \\
\hline F2 & M25 & $\begin{array}{l}\text { Had difficulty finding a suitable place to } \\
\text { dry my menstrual cloth }\end{array}$ & 01 & 02 & 03 & 04 \\
\hline Deleted & M26 & Felt like vomiting during menstruation & 01 & 02 & 03 & 04 \\
\hline Deleted & M27 & $\begin{array}{l}\text { Had a lot of cleaning work to do because } \\
\text { of menstruation }\end{array}$ & 01 & 02 & 03 & 04 \\
\hline F5 & M28 & $\begin{array}{c}\text { Got wounds on inner thighs from cloth } \\
\text { or belt }\end{array}$ & 01 & 02 & 03 & 04 \\
\hline F2 & M29 & $\begin{array}{l}\text { Had difficulty finding a place to change } \\
\text { menstrual materials (cloth or pad) }\end{array}$ & 01 & 02 & 03 & 04 \\
\hline Deleted & M30 & $\begin{array}{l}\text { Had difficulty doing my regular work } \\
\text { during menstruation }\end{array}$ & 01 & 02 & 03 & 04 \\
\hline Deleted & M31 & $\begin{array}{l}\text { Had difficulty fetching water for } \\
\text { menstruation related needs }\end{array}$ & 01 & 02 & 03 & 04 \\
\hline Deleted & M32 & $\begin{array}{l}\text { Had difficulty urinating while } \\
\text { menstruating }\end{array}$ & 01 & 02 & 03 & 04 \\
\hline F2 & M33 & $\begin{array}{l}\text { Had difficulty finding a place to dispose } \\
\text { of cloth or pad }\end{array}$ & 01 & 02 & 03 & 04 \\
\hline Deleted & M34 & $\begin{array}{l}\text { Had difficulty walking during } \\
\text { menstruation }\end{array}$ & 01 & 02 & 03 & 04 \\
\hline Deleted & M35 & $\begin{array}{l}\text { Was forced to conform to a restriction } \\
\text { that I do not believe in }\end{array}$ & 01 & 02 & 03 & 04 \\
\hline Deleted & M36 & $\begin{array}{l}\text { Had people tease me because they knew } \\
\text { I was menstruating }\end{array}$ & 01 & 02 & 03 & 04 \\
\hline F4 & M37 & $\begin{array}{l}\text { Worried that my cycle was irregular } \\
\text { Had difficulty finding someone to help }\end{array}$ & 01 & 02 & 03 & 04 \\
\hline F2 & M38 & $\begin{array}{c}\text { me with bathing } \\
\text { and other menstruation-related needs at } \\
\text { onset }\end{array}$ & 01 & 02 & 03 & 04 \\
\hline F2 & M39 & $\begin{array}{l}\text { Had difficulty finding a place to store } \\
\text { menstrual cloth or pads }\end{array}$ & 01 & 02 & 03 & 04 \\
\hline F2 & M40 & $\begin{array}{l}\text { Had to stay separated at night from my } \\
\text { normal bed }\end{array}$ & 01 & 02 & 03 & 04 \\
\hline
\end{tabular}


Table A1. Cont.

\begin{tabular}{|c|c|c|c|c|c|c|}
\hline \multicolumn{7}{|c|}{ How Often Have You Experienced Any of the Following during Your Last Two Menstrual Periods? } \\
\hline Factor & Item No. & Item & Never & Some-Times & Often & Always \\
\hline $\mathrm{F} 4$ & M41 & $\begin{array}{l}\text { Worried about my health because of } \\
\text { problems with my menstrual cycle }\end{array}$ & 01 & 02 & 03 & 04 \\
\hline Deleted & M42 & $\begin{array}{l}\text { Worried about being treated as } \\
\text { untouchable by others }\end{array}$ & 01 & 02 & 03 & 04 \\
\hline Deleted & M43 & $\begin{array}{l}\text { Had to wear cloth that was not fully dry } \\
\text { after washing }\end{array}$ & 01 & 02 & 03 & 04 \\
\hline F5 & M44 & $\begin{array}{l}\text { Had trouble doing my work because of } \\
\text { wound from cloth/pad }\end{array}$ & 01 & 02 & 03 & 04 \\
\hline Deleted & M45 & $\begin{array}{l}\text { Have a general feeling of tension at } \\
\text { onset of menstruation }\end{array}$ & 01 & 02 & 03 & 04 \\
\hline Deleted & M46 & $\begin{array}{l}\text { Was prevented from going to certain } \\
\text { places that I wanted to go }\end{array}$ & 01 & 02 & 03 & 04 \\
\hline F4 & M47 & $\begin{array}{l}\text { Worried about ability to become } \\
\text { pregnant because of problems with my } \\
\text { menstrual cycle }\end{array}$ & 01 & 02 & 03 & 04 \\
\hline F5 & M48 & $\begin{array}{l}\text { Worried that my cloth, napkin or my } \\
\text { body smelled }\end{array}$ & 01 & 02 & 03 & 04 \\
\hline Deleted & M49 & $\begin{array}{l}\text { Worried that others knew I was } \\
\text { menstruating }\end{array}$ & 01 & 02 & 03 & 04 \\
\hline
\end{tabular}

\section{References}

1. Sommer, M.; Hirsch, J.S.; Nathanson, C.; Parker, R.G. Comfortably, Safely, and Without Shame: Defining Menstrual Hygiene Management as a Public Health Issue. Am. J. Public Health 2015, 105, 1302-1311. [CrossRef] [PubMed]

2. Bobel, C. Making menstruation matter in the global south: Mapping a critical history. In The Managed Body; Palgrave Macmillan: Cham, Switzerland, 2019; pp. 69-109.

3. Sinden, J.; Sahin, M.; Francois, C. WASH in Schools for Girls: Voices from the Field-Advocacy and Capacity Building for Menstrual Hygiene Management through WASH in Schools Programmes; UNICEF: New York, NY, USA, 2015.

4. Phillips-Howard, P.; Caruso, B.A.; Torondel, B.; Zulaika, G.; Sahin, M.; Sommer, M. Menstrual hygiene management among adolescent schoolgirls in low- and middle-income countries: Research priorities. Glob. Health Action 2016, 9. [CrossRef] [PubMed]

5. Sommer, M.; Caruso, B.A.; Sahin, M.; Calderon, T.; Cavill, S.; Mahon, T.; Phillips-Howard, P.A. A time for global action: Addressing girls' menstrual hygiene management needs in schools. PLoS Med. 2016, 13, e1001962. [CrossRef] [PubMed]

6. Sommer, M.; Zulaika, G.; Schmitt, M.; Gruer, C. (Eds.) Monitoring Menstrual Health and Hygiene: Measuring Progress for Girls on Menstruation; Meeting Report; Columbia University and WSSCC: New York, NY, USA; Geneva, Switzerland, 2019.

7. Huggett, C.; Zielinski, D.; Nee, M.; International Planned Parenthood Federation; International Women's Health Coalition; Marie Stopes International; Simavi; WaterAid. A Shared Agenda: Exploring Links between Water, Sanitation, Hygiene, and Sexual and Reproductive Health and Rights in Sustainable Development. WaterAid. 2019. Available online: https://www.mariestopes.org/media/3673/a-shared-agenda.pdf (accessed on 2 May 2020).

8. Hennegan, J.; Shannon, A.K.; Rubli, J.; Schwab, K.J.; Melendez-Torres, G. Women's and girls' experiences of menstruation in low-and middle-income countries: A systematic review and qualitative metasynthesis. PLoS Med. 2019, 16, e1002803. [CrossRef]

9. Caruso, B.A.; Sommer, M.; Phillips-Howard, P.A. All of women's health needs are worthy of attention. Lancet 2019, 393, 2119. [CrossRef]

10. Sahoo, K.C.; Hulland, K.R.; Caruso, B.A.; Swain, R.; Freeman, M.C.; Panigrahi, P.; Dreibelbis, R. Sanitation-related psychosocial stress: A grounded theory study of women across the life-course in Odisha, India. Soc. Sci. Med. 2015, 139, 80-89. [CrossRef] 
11. Hulland, K.R.; Chase, R.P.; Caruso, B.A.; Swain, R.; Biswal, B.; Sahoo, K.C.; Panigrahi, P.; Dreibelbis, R. Sanitation, Stress, and Life Stage: A Systematic Data Collection Study among Women in Odisha, India. PLoS ONE 2015, 10, e0141883. [CrossRef]

12. MacRae, E.R.; Clasen, T.; Dasmohapatra, M.; Caruso, B.A. 'It's like a burden on the head': Redefining adequate menstrual hygiene management throughout women's varied life stages in Odisha, India. PLoS ONE 2019, 14, e0220114. [CrossRef]

13. Walraven, G.; Ekpo, G.; Coleman, R.; Scherf, C.; Morison, L.; Harlow, S.D. Menstrual disorders in rural Gambia. Stud. Fam. Plann. 2002, 33, 261-268. [CrossRef]

14. Hemachandra, D.K.; Manderson, L. Menstrual problems and health seeking in Sri Lanka. Women Health 2009, 49, 405-421. [CrossRef] [PubMed]

15. Wall, L.L.; Belay, S.; Bayray, A.; Salih, S.; Gabrehiwot, M. A community-based study of menstrual beliefs in Tigray, Ethiopia. Int. J. Gynecol. Obs. 2016, 135, 310-313. [CrossRef] [PubMed]

16. Umeora, O.U.; Egwuatu, V.E. Menstruation in rural Igbo women of south east Nigeria: Attitudes, beliefs and practices. Afr. J. Reprod. Health 2008, 12, 109-115. [PubMed]

17. Scorgie, F.; Foster, J.; Stadler, J.; Phiri, T.; Hoppenjans, L.; Rees, H.; Muller, N. “Bitten By Shyness": Menstrual Hygiene Management, Sanitation, and the Quest for Privacy in South Africa. Med. Anthr. 2016, 35, 161-176. [CrossRef] [PubMed]

18. Garg, S.; Sharma, N.; Sahay, R. Socio-cultural aspects of menstruation in an urban slum in Delhi, India. Reprod. Health Matters 2001, 9, 16-25. [CrossRef]

19. do Amaral, M.C.E.; Hardy, E.; Hebling, E.M. Menarche among Brazilian women: Memories of experiences. Midwifery 2011, 27, 203-208. [CrossRef]

20. Crawford, M.; Menger, L.M.; Kaufman, M.R. 'This is a natural process': Managing menstrual stigma in Nepal. Cult. Health Sex. 2014, 16, 426-439. [CrossRef]

21. Castaneda, X.; Garcia, C.; Langer, A. Ethnography of fertility and menstruation in rural Mexico. Soc. Sci. Med. 1996, 42, 133-140. [CrossRef]

22. Caruso, B.A.; Clasen, T.F.; Hadley, C.; Yount, K.M.; Haardörfer, R.; Rout, M.; Dasmohapatra, M.; Cooper, H.L. Understanding and defining sanitation insecurity: Women's gendered experiences of urination, defecation and menstruation in rural Odisha, India. BMJ Glob. Health 2017, 2, e000414. [CrossRef]

23. Thomson, J.; Amery, F.; Channon, M.; Puri, M. What's missing in MHM? Moving beyond hygiene in menstrual hygiene management. Sex. Reprod. Health Matters 2019, 27, 1684231. [CrossRef]

24. Hennegan, J.; Zimmerman, L.; Shannon, A.K.; Exum, N.G.; OlaOlorun, F.; Omoluabi, E.; Schwab, K.J.; Investigators, P. The Relationship between Household Sanitation and Women's Experience of Menstrual Hygiene: Findings from a Cross-Sectional Survey in Kaduna State, Nigeria. Int. J. Environ. Res. Public Health 2018, 15, 905. [CrossRef] [PubMed]

25. Cardoso, L.F.; Clark, C.J.; Rivers, K.; Ferguson, G.; Shrestha, B.; Gupta, J. Menstrual restriction prevalence and association with intimate partner violence among Nepali women. BMJ Sex. Reprod. Health 2019, 45, 38-43. [CrossRef]

26. Phillips-Howard, P.A.; Otieno, G.; Burmen, B.; Otieno, F.; Odongo, F.; Odour, C.; Nyothach, E.; Amek, N.; Zielinski-Gutierrez, E.; Odhiambo, F.; et al. Menstrual Needs and Associations with Sexual and Reproductive Risks in Rural Kenyan Females: A Cross-Sectional Behavioral Survey Linked with HIV Prevalence. J. Womens Health 2015, 24, 801-811. [CrossRef] [PubMed]

27. Hennegan, J.; Nansubuga, A.; Smith, C.; Redshaw, M.; Akullo, A.; Schwab, K.J. Measuring menstrual hygiene experience: Development and validation of the Menstrual Practice Needs Scale (MPNS-36) in Soroti, Uganda. BMJ Open 2020, 10, e034461. [CrossRef] [PubMed]

28. Boateng, G.O.; Neilands, T.B.; Frongillo, E.A.; Melgar-Quinonez, H.R.; Young, S.L. Best Practices for Developing and Validating Scales for Health, Social, and Behavioral Research: A Primer. Front. Public Health 2018, 6, 149. [CrossRef] [PubMed]

29. Frongillo, E.; Nanama, S.; Wolfe, W. Technical Guide to Developing a Direct, Experience-based Measurement Tool for Household Food Insecurity; Food and Nutrition Technical Assistance Project, Academy for Educational Development: Washington, DC, USA, 2004; pp. 1-51.

30. Frongillo, E.A.; Nanama, S. Development and validation of an experience-based measure of household food insecurity within and across seasons in northern Burkina Faso. J. Nutr. 2006, 136, 1409S-1419S. [CrossRef] [PubMed] 
31. Wolfe, W.S.; Frongillo, E.A. Building household food-security measurement tools from the ground up. Food Nutr. Bull. 2001, 22, 5-12. [CrossRef]

32. Stevenson, E.G.; Greene, L.E.; Maes, K.C.; Ambelu, A.; Tesfaye, Y.A.; Rheingans, R.; Hadley, C. Water insecurity in 3 dimensions: An anthropological perspective on water and women's psychosocial distress in Ethiopia. Soc. Sci. Med. 2012, 75, 392-400. [CrossRef]

33. Boateng, G.O.; Collins, S.M.; Mbullo, P.; Wekesa, P.; Onono, M.; Neilands, T.B.; Young, S.L. A novel household water insecurity scale: Procedures and psychometric analysis among postpartum women in western Kenya. PLoS ONE 2018, 13, e0198591. [CrossRef]

34. Young, S.L.; Boateng, G.O.; Jamaluddine, Z.; Miller, J.D.; Frongillo, E.A.; Neilands, T.B.; Collins, S.M.; Wutich, A.; Jepson, W.E.; Stoler, J.; et al. The Household Water InSecurity Experiences (HWISE) Scale: Development and validation of a household water insecurity measure for low-income and middle-income countries. BMJ Glob. Health 2019, 4, e001750. [CrossRef]

35. Caruso, B.A.; Clasen, T.; Yount, K.M.; Cooper, H.L.; Hadley, C.; Haardörfer, R. Assessing Women's Negative Sanitation Experiences and Concerns: The Development of a Novel Sanitation Insecurity Measure. Int. J. Environ. Res. Public Health 2017, 14, 755. [CrossRef] [PubMed]

36. Hadley, C.; Wutich, A. Experience-based measures of food and water security: Biocultural approaches to grounded measures of insecurity. Hum. Organ. 2009, 68, 451-460. [CrossRef]

37. Jepson, W.E.; Wutich, A.; Colllins, S.M.; Boateng, G.O.; Young, S.L. Progress in household water insecurity metrics: A cross-disciplinary approach. Wiley Interdiscip. Rev. Water 2017, 4, e1214. [CrossRef]

38. WHO; UNICEF. Progress on Drinking Water and Sanitation: 2015 Update and MDG Assessment; WHO; UNICEF: Geneva, Switzerland, 2015.

39. International Institute for Population Sciences (IIPS) and ICF. National Family Health Survey (NFHS-4), 2015-2016: India; IIPS: Mumbai, India, 2017.

40. Das, P.; Baker, K.K.; Dutta, A.; Swain, T.; Sahoo, S.; Das, B.S.; Panda, B.; Nayak, A.; Bara, M.; Bilung, B.; et al. Menstrual Hygiene Practices, WASH Access and the Risk of Urogenital Infection in Women from Odisha, India. PLoS ONE 2015, 10, e0130777. [CrossRef] [PubMed]

41. Clasen, T.; Boisson, S.; Routray, P.; Torondel, B.; Bell, M.; Cumming, O.; Ensink, J.; Freeman, M.; Jenkins, M.; Odagiri, M. Effectiveness of a rural sanitation programme on diarrhoea, soil-transmitted helminth infection, and child malnutrition in Odisha, India: A cluster-randomised trial. Lancet Glob. Health 2014, 2, e645-e653. [CrossRef]

42. Clasen, T.; Boisson, S.; Routray, P.; Cumming, O.; Jenkins, M.; Ensink, J.H.; Bell, M.; Freeman, M.C.; Peppin, S.; Schmidt, W.-P. The effect of improved rural sanitation on diarrhoea and helminth infection: Design of a cluster-randomized trial in Orissa, India. Emerg. Themes Epidemiol. 2012, 9, 7. [CrossRef] [PubMed]

43. Boisson, S.; Sosai, P.; Ray, S.; Routray, P.; Torondel, B.; Schmidt, W.-P.; Bhanja, B.; Clasen, T. Promoting latrine construction and use in rural villages practicing open defecation: Process evaluation in connection with a randomised controlled trial in Orissa, India. BMC Res. Notes 2014, 7, 486. [CrossRef]

44. Schensul, J.; LeCompte, M.D.; Nastasi, B.K.; Borgatti, S.P. Elicitation Techniques for Cultural Domain Analysis. Enhanced Ethnographic Methods: Audiovisual Techniques, Focused Group Interviews, and Elicitation Techniques; Altamira Press: Walnut Creek, CA, USA, 1999; pp. 115-151.

45. De-Vet, H.; Terwee, C.; Mokkink, L.; KNOL, D. Measurement in Medicine; Cambridge University Press: Cambridge, UK, 2011.

46. Beatty, P.C.; Willis, G.B. Research Synthesis: The Practice of Cognitive Interviewing. Public Opin. Q. 2007, 71, 287-311. [CrossRef]

47. Diez-Roux, A.V. Multilevel analysis in public health research. Annu. Rev. Public Health 2000, 21, 171-192. [CrossRef]

48. Caruso, B.A.; Cooper, H.L.F.; Haardorfer, R.; Yount, K.M.; Routray, P.; Torondel, B.; Clasen, T. The association between women's sanitation experiences and mental health: A cross-sectional study in Rural, Odisha India. SSM Popul. Health 2018, 5, 257-266. [CrossRef]

49. Estes, K. Sample Size Recommendations in Hierarchical Linear Modeling: A Monte Carlo Simulation of $n$ and Predictor-criterion Correlations; Georgia State University: Atlanta, GA, USA, 2008.

50. Bandalos, D.; Finney, S. Factor analysis: Exploratory and confirmatory. In The Reviewer's Guide to Quantitative Methods in the Social Sciences; Hancock, G.R., Mueller, R.O., Eds.; Routledge: New York, NY, USA, 2010; pp. 93-114. 
51. Zwick, W.R.; Velicer, W.F. Comparison of five rules for determining the number of components to retain. Psychol. Bull. 1986, 99, 432. [CrossRef]

52. Hair, J.F.; Black, W.C.; Babin, B.J.; Anderson, R.E.; Tatham, R.L. Multivariate Data Analysis; Prentice Hall: Upper Saddle River, NJ, USA, 1998; Volume 5.

53. Hair, J., Jr.; Black, W.; Babin, B.; Anderson, R. Multivariate Data Analysis, 7th ed.; Pearson Education Limited: Essex, UK, 2014.

54. McMahon, S.A.; Winch, P.J.; Caruso, B.A.; Obure, A.F.; Ogutu, E.A.; Ochari, I.A.; Rheingans, R.D. 'The girl with her period is the one to hang her head' Reflections on menstrual management among schoolgirls in rural Kenya. BMC Int. Health Hum. Rights 2011, 11, 7. [CrossRef] [PubMed]

55. Mason, L.; Nyothach, E.; Alexander, K.; Odhiambo, F.O.; Eleveld, A.; Vulule, J.; Rheingans, R.; Laserson, K.F.; Mohammed, A.; Phillips-Howard, P.A. 'We Keep It Secret So No One Should Know': A Qualitative Study to Explore Young Schoolgirls Attitudes and Experiences with Menstruation in Rural Western Kenya. PLoS ONE 2013, 8, e79132. [CrossRef] [PubMed]

56. Dolan, C.S.; Ryus, C.R.; Dopson, S.; Montgomery, P.; Scott, L. A blind spot in girls'education: menarche and its webs of exclusion in Ghana. J. Int. Dev. 2013, 26, 643-657. [CrossRef]

57. Weaver, L.J. Tension among women in North India: An idiom of distress and a cultural syndrome. Cult. Med. Psychiatry 2017, 41, 35-55. [CrossRef]

58. Bobel, C. The Managed Body: Developing Girls and Menstrual Health in the Global South; Palgrave Macmillan: Cham, Switzerland, 2019.

59. Sommer, M.; Chandraratna, S.; Cavill, S.; Mahon, T.; Phillips-Howard, P. Managing menstruation in the workplace: An overlooked issue in low-and middle-income countries. Int. J. Equity Health 2016, 15, 1. [CrossRef]

60. Hoffmann, D.E.; Tarzian, A.J. The girl who cried pain: A bias against women in the treatment of pain. J. Law Med. Ethics 2001, 29, 13-27. [CrossRef]

61. Moos, R.H. The development of a menstrual distress questionnaire. Psychosom. Med. 1968, 30, 853-867. [CrossRef]

62. Stephenson, L.A.; Denney, D.R.; Aberger, E.W. Factor structure of the menstrual symptom questionnaire: Relationship to oral contraceptives, neuroticism and life stress. Behav. Res. Ther. 1983, 21, 129-135. [CrossRef]

63. van Eijk, A.M.; Sivakami, M.; Thakkar, M.B.; Bauman, A.; Laserson, K.F.; Coates, S.; Phillips-Howard, P.A. Menstrual hygiene management among adolescent girls in India: A systematic review and meta-analysis. BMJ Open 2016, 6, e010290. [CrossRef]

64. Long, J.; Caruso, B.A.; Lopez, D.; Vancraeynest, K.; Sahin, M.; Andes, K.L.; Freeman, M.C. WASH in Schools Empowers Girls' Education in Rural Cochabamba, Bolivia: An Assessment of Menstrual Hygiene Management in Schools; United Nations Children's Fund: New York, NY, USA, 2013.

65. Haver, J.; Caruso, B.A.; Ellis, A.; Sahin, M.; Villasenor, J.M.; Andes, K.L.; Freeman, M.C. WASH in Schools Empowers Girls' Education in Masbate Province and Metro Manila, Philippines An Assessment of Menstrual Hygiene Management in Schools; United Nation Children's Fund: New York, NY, USA, 2013.

66. Caruso, B.A.; Fehr, A.; Inden, K.; Ellis, A.; Andes, K.L.; Freeman, M.C. WASH in Schools Empowers Girls' Education in Freetown, Sierra Leone: An Assessment of Menstrual Hygiene Management in Schools; UNICEF: New York, NY, USA, 2013.

67. Routray, P.; Schmidt, W.-P.; Boisson, S.; Clasen, T.; Jenkins, M.W. Socio-cultural and behavioural factors constraining latrine adoption in rural coastal Odisha: An exploratory qualitative study. BMC Public Health 2015, 15, 880. [CrossRef] [PubMed]

68. Coffey, D.; Gupta, A.; Hathi, P.; Khurana, N.; Spears, D.; Srivastav, N.; Vyas, S. Revealed preference for open defecation. Econ. Political Wkly. 2014, 49, 43.

69. Schmitt, M.L.; Clatworthy, D.; Ogello, T.; Sommer, M. Making the Case for a Female-Friendly Toilet. Water 2018, 10, 1193. [CrossRef]

70. Garg, R.; Goyal, S.; Gupta, S. India moves towards menstrual hygiene: Subsidized sanitary napkins for rural adolescent girls-issues and challenges. Matern. Child Health J. 2012, 16, 767-774. [CrossRef] [PubMed] 
71. Aylward, P.; Little, K.; Sharma, V.; Satpati, M.; Singh, A.; Ahmed, F.; Punzi, M.; Rosenberg, S.; Caruso, B. Increasing Access to Menstrual Hygiene Products in India: A Market Development Approach; psi: Washington, DC, USA, 2018.

72. Chandra-Mouli, V.; Patel, S.V. Mapping the knowledge and understanding of menarche, menstrual hygiene and menstrual health among adolescent girls in low-and middle-income countries. Reprod. Health 2017, 14, 30. [CrossRef] [PubMed]

(C) 2020 by the authors. Licensee MDPI, Basel, Switzerland. This article is an open access article distributed under the terms and conditions of the Creative Commons Attribution (CC BY) license (http://creativecommons.org/licenses/by/4.0/). 